Article

\title{
Carbon Capture and Storage Development Trends from a Techno-Paradigm Perspective
}

\author{
Bobo Zheng ${ }^{1}$ and Jiuping Xu ${ }^{1,2, *}$ \\ ${ }^{1}$ Low Carbon Technology and Economy Research Center, Sichuan University, \\ Chengdu 610064, China; E-Mail: bobogeorge@163.com \\ ${ }^{2}$ Business School, Sichuan University, Chengdu 610064, China \\ * Author to whom correspondence should be addressed; E-Mail: xujiuping@ @scu.edu.cn; \\ Tel.: +86-28-8541-8522; Fax: +86-28-8541-5143.
}

Received: 5 June 2014; in revised form: 8 July 2014 / Accepted: 11 August 2014 /

Published: 14 August 2014

\begin{abstract}
The world's energy needs have been continually growing over the past decade, yet fossil fuels are limited. Renewable energies are becoming more prevalent, but are still a long way from being commonplace worldwide. Literature mining is applied to review carbon capture and storage (CCS) development trends and to develop and examine a novel carbon capture and storage technological paradigm (CCSTP), which incorporates CCSTP competition, diffusion and shift. This paper first provides an overview of the research and progress in CCS technological development, then applies a techno-paradigm theory to analyze CCSTP development and to provide a guide for future CCS technological trends. CCS could avoid $\mathrm{CO}_{2}$ being released into the atmosphere. Moreover, bioenergy with CCS (BECCS) can make a significant contribution to a net removal of anthropogenic $\mathrm{CO}_{2}$ emissions. In this study, we compare the different CCSTP developmental paths and the conventional techno-paradigm by examining the S-curves. The analyses in this paper provide a useful guide for scholars seeking new inspiration in their research and for potential investors who are seeking to invest research funds in more mature technologies. We conclude that political barriers and public acceptance are the major distinctions between the CCSTP and the conventional techno-paradigm. It is expected that policy instruments and economic instruments are going to play a pivotal role in the accomplishment of global carbon reduction scenarios.
\end{abstract}


Keywords: climate mitigation; bioenergy with CCS; literature mining; carbon capture utilization and storage; techno-paradigm

\section{Introduction}

There is an inextricable relationship between energy demand and economic progress. Driven by the twin forces of population growth and economic prosperity, global energy demand continues to soar as society pushes for higher living standards [1]. In 1977, Marchetti [2] suggested that rising atmospheric $\mathrm{CO}_{2}$ levels were a result of the burning of fossil fuels, and since this time, this issue has become increasingly severe globally. Climate change has now been directly attributed to air toxicants and greenhouse gases (GHG) and especially to the build-up of $\mathrm{CO}_{2}$, and it has become generally accepted that GHG emissions control is the most challenging environmental policy issue worldwide. According to Houghton et al. [3] and Watson and Albritton [4], anthropogenic $\mathrm{CO}_{2}$ emission concentrations have increased from a pre-industrial level of $280 \mathrm{ppm}$ to over $380 \mathrm{ppm}$ today. As a result, the global mean surface temperature has increased by $0.6 \pm 0.2{ }^{\circ} \mathrm{C}$ during the 20th century [3]. In Peters et al. [5], global carbon emissions were shown to have incrementally increased by an average of $3 \%$ per year since 2000 . The International Panel on Climate Change (IPCC) forecast that atmospheric $\mathrm{CO}_{2}$ concentrations may reach 570 ppm by 2100 , leading to global climatic impacts, such as a rise in the mean global temperature of around $1.9^{\circ} \mathrm{C}$ and an increase in mean sea level of $38 \mathrm{~cm} \mathrm{[6].} \mathrm{While} \mathrm{previously,} \mathrm{these} \mathrm{emissions} \mathrm{were}$ mainly from developed countries, increasingly, developing countries are contributing to the rising carbon emissions, as can be evidenced in the results of urbanization in China [7]. Pacala and Socolow [8] and Mathews [9] showed that there was a net carbon addition of around 4 Gt, called the "carbon flux", each year as a result of the combustion of conventional fuels and industrial processes (Figure 1) and further pointed out that it is possible that global carbon levels would be nearing $1000 \mathrm{Gt}$, or the "overflow point", by 2050 [9].

Figure 1. The atmosphere as a "carbon tank".

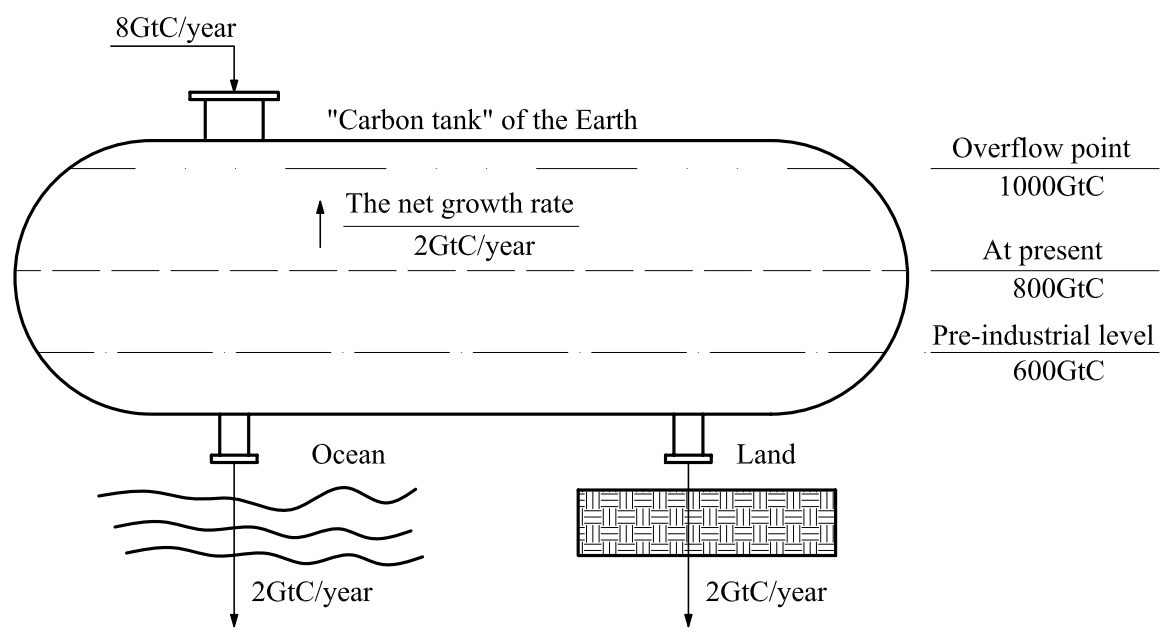


To achieve cost optimized scenario of IEA [10] for the stabilization of $\mathrm{CO}_{2}$ emissions at $450 \mathrm{ppm}$ by 2050 , there needs to be a technological energy revolution involving a portfolio of integrated solutions, such as greater primary energy conversion and end-use efficiency, the commercialization of renewable energy technologies, the enhancement of nuclear power use and the de-carbonization of conventional power generation using carbon capture and storage (CCS). People, businesses and governments also need to reduce their global energy consumption, either through the utilization of more efficient technologies or through changes in lifestyle and behavior, or both. Developing and implementing sustainable energy policies is the most obvious path, which would not only provide sufficient energy, but also protect the environment and ecosystem integrity. However, at present, because of technical barriers and a lack of capital, renewable energy technologies are not financially viable for most countries. Conventional fossils fuels, such as oil, coal and natural gas, on the other hand, remain the most economically available, convenient source of energy. Considering these factors, CCS could play a positive role in immediately mitigating carbon emissions [11]. CCS technologies can be seen as a chain of technologies created to capture $\mathrm{CO}_{2}$ from industrial atmosphere [12]. Furthermore, CCS has also proven to be an important technology in seeking a reduction in overall stabilization costs [13]. The studies of IEA [10] studies strongly agree with this viewpoint, indicating that $19 \%$ of total emissions reductions could come as a result of CCS. Consequently, CCS has gained ground as an important part of environmental policy blueprints in many countries [14]. Although they are not yet classified as real renewable technologies, CCS methodologies are an important bridge between our current lifestyles and an environmentally-friendly world. In the latest IPCC Fifth Assessment Report (AR5), it strongly suggested that some negative emissions approaches are required to address the proposed $\mathrm{CO}_{2}$ mitigation goal. Bioenergy with carbon capture and storage (BECCS), as one of the promising alternatives, is expected to play a key role in abating anthropogenic $\mathrm{CO}_{2}$ concentrations [15].

In 2003, the British Government published an "Energy White Paper" [16], which was the first to propose the concept of a "low-carbon economy" by focusing on a reduction in both the consumption of natural resources and environmental pollution levels to increase economic output and showed that economic development and technological innovation were closely related to each other. In this context, Pearson and Foxon [17] suggested that the use of low carbon technologies could affect many areas of the economy by promoting technical innovation in the financial, economic, environmental and social markets. Moreover, the availability of these technologies has been identified as a key influence in reducing global mitigation costs [18].

Kuhn [19] first defined a paradigm as a coherent pattern of research designed around commonly held theoretical propositions and models. Dosi [20] believed that the theories of technical change have generally followed two different basic approaches. One of these is "demand-pull" theory, which states that market forces are the determining factor for technical change. The other is "technology-push" theory, which sees technology as an independent factor. Freeman [21] suggested that a new innovative pattern needs to be developed for large techno-economic system transitions. Van den Ende and Dolfsma [22] believe that the development of techno-paradigms is a result of the effects of push and pull, namely supply and demand. In competitive markets, Grübler et al. [23] outlined how patterns, processes and timescales are characteristic of the new technological diffusion. A typical long-term technology, which is an element in interlocking networks, generally requires a long time to 
diffuse and simultaneously develop with other technologies in the network. With the sharp deterioration in the environment, scientists around the world have become increasingly focused on research into low-carbon technological innovations and low-carbon economic development. Consequently, they have made outstanding achievements in GHG reductions and have had a positive influence on the development of global low-carbon economies. As a result, due to the lack of a systematic analytical framework for low-carbon technologies, much of the research in this area has had little integrity or universality. Moreover, as there have been few studies that have specifically examined the low carbon techno-paradigm or, in particular, the CCS technological paradigm, progress in this area has been slow, with previous achievements partially overlapping and therefore adding little to the field.

From the research mentioned, in this paper, we introduce the CCS techno-paradigm (CCSTP) concept, which is a member of the technological family universally relied on for the development of future mitigation and stabilization scenarios [24]. Through an analysis of the development of some analogous industries, such as the $\mathrm{SO}_{2}$-scrubber industry and the global liquefied natural gas industry (LNG) [25], we can conclude that the CCSTP meets the laws of the development paradigm and also has three similar stages: CCSTP competition, CCSTP diffusion and CCSTP shift, as shown in Table 1.

Table 1. The carbon capture and storage techno-paradigm (CCSTP) framework.

\begin{tabular}{ccc}
\hline Stage Name & Representative Technology & Technical Barriers \\
\hline Competition & Carbon capture & $\begin{array}{c}\text { About both R\&D to build up the key technological } \\
\text { system and also the creation of nascent markets in } \\
\text { which the technology can be deployed and proven }\end{array}$ \\
\hline Diffusion & Carbon storage & $\begin{array}{c}\text { Lower the business risk of large-scale; reduce } \\
\text { financial risk and acquiring operating experience } \\
\text { in pilot-scale tests }\end{array}$ \\
\hline Shift & Carbon utilization & $\begin{array}{c}\text { Carbon capture and storage technologies would } \\
\text { come into being mature }\end{array}$ \\
\hline
\end{tabular}

As shown in Figure 2, along the classic "S-curve", there is an assumption that any new technology experiences these three phases. The first phase is defined as competition and is recognized and adopted by early followers. Diffusion is the second phase in which the new technology prevails in the potential market. Ultimately, with the technology beginning to saturate its natural market, there is a technological shift, which leads to the third phase [25]. However, technological development is not discrete, but alternates in an S-curve way on the basis of technological continuity. Following this rule, we hold that, in practice, the CCSTP has the possibility of breaking technical barriers and reducing business costs in the future. In this paper, we define a new CCSTP concept, review existing CCS technologies, and analyze the formation process for the CCSTP by applying a conventional theoretical paradigm framework. Further, we make recommendations for the evolution of CCS technologies over the next few decades.

The remainder of this paper is organized as follows: Section 2 reports on the results of the literature mining to filter the CCS development trends. Section 3 provides an overview of CCS techno-paradigm, and then, Section 4 analyzes and discusses the major distinctions between the 
conventional techno-paradigm and the CCSTP. Section 5 gives conclusions and recommendations for future research.

Figure 2. The growing trend of the techno-paradigm.

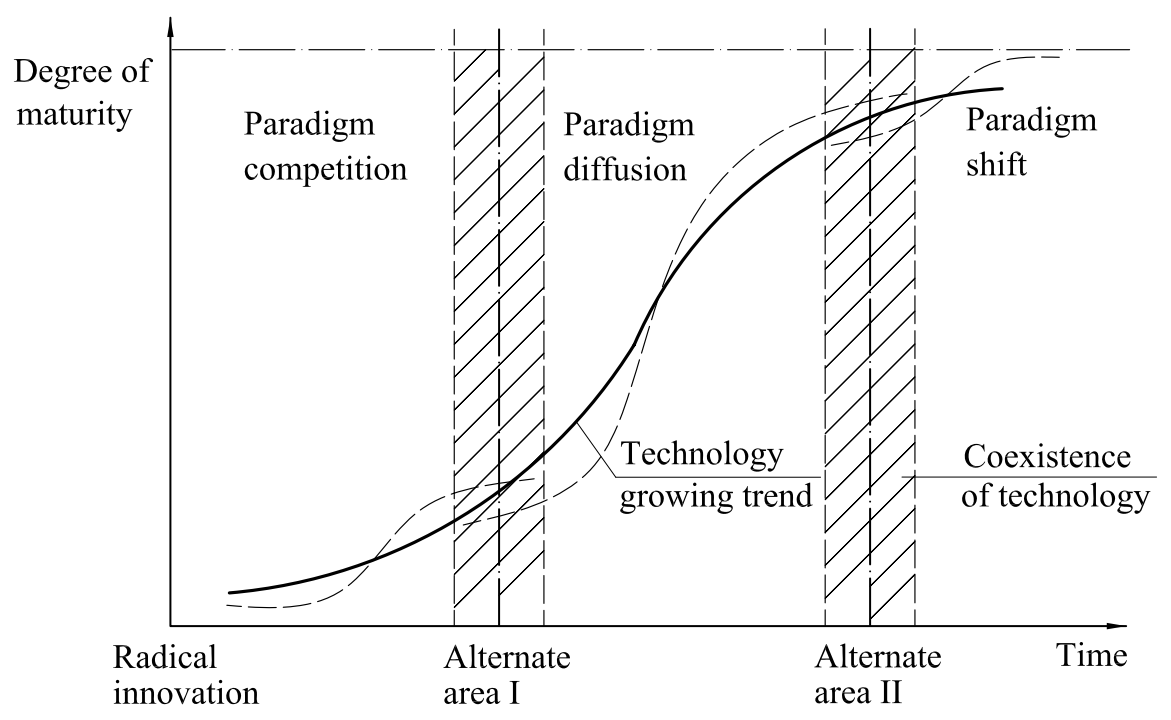

\section{Literature Mining}

With the vast quantity of research about carbon sequestration and storage and utilization technologies, it is extremely difficulty to analyze and uncover which issues are research hot spots [26]. Since the Greenhouse Gas Control Technologies (GHGT) conference series was established in 1997, the number of research articles in CCS-related fields has expanded significantly. Literature mining, as an effective approach, has been used to identify past and present research, as well as to predict prospective orientations [27]. Through this process, relationship networks based on research keywords and their published years of specific papers can be effectively identified [28].

Peer-reviewed scientific literature can assist potential researchers to identify the latest developments and ascertain the future directions of a specific research field [29]. Using literature mining methods, more than 300 published scientific research papers have been identified in many well-known journals [30,31]. Further, many analyses based on this scientific research have been published in the IPCC-AR5 [15]. It has been shown, therefore, that applying literature mining to a research field, such as CCS, can identify key areas in carbon capture, sequestration and utilization and provide predictions for future trends; so, this is the principal method used in this article.

\subsection{The Data Analysis System}

Garfield and Merton [32] first proposed that the citation indexing of academic literature is crucial for the bonding of similar research topics. A citation index is a synthesized result based on journal articles, keywords, publication dates and abstracts and is able to demonstrate the influences in a specific field. Therefore, for our research, it is essential to construct a sufficient and effective data analysis system based on keywords and publication dates [33]. As a comprehensive meta-synthesis approach, the data 
analysis system (DAS) is mainly composed of the ISI Web of Science database (WoS), NoteExpress and NodeXL, the framework for which is outlined in Figure 3.

Figure 3. The framework of a data analysis system.

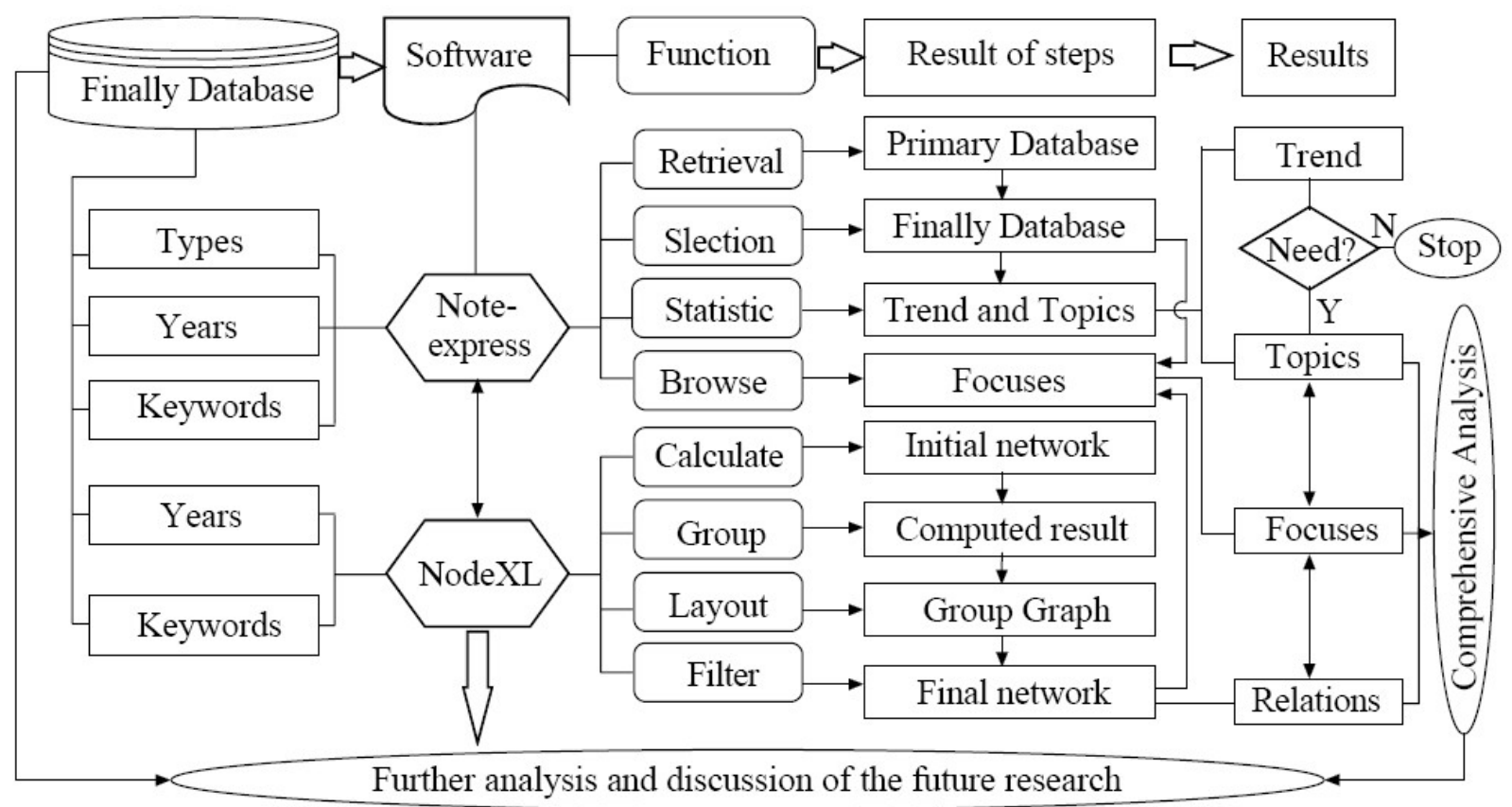

\subsection{Analyzing the Literature}

Carbon research development can be divided into three main groups; capture, storage and utilization. As shown in Table 2, we defined the specific topics by using a Boolean search to screen and filter the useful information. Through a four-step filtering process, the initial result of 279,676 peer-reviewed papers was screened down to 1398 articles. Taking representativeness and integrity into account, the 2014 articles were filtered out, leaving 1333 research papers in the final DAS, as shown in Figure 4. From this analysis, it can be clearly seen that the number of research papers have gradually increased since the Kyoto Protocol was formally published in December, 1997 [34], and when an agreement was arrived at in the Bali Road Map meeting in 2007, there was a sharper increase in published papers [35]. Here, we introduce the WoS to evaluate selected articles' appropriateness and accuracy [26]. 
Table 2. Selection criteria for carbon research.

\begin{tabular}{ccl}
\hline No. & Quantity & Selection Criteria \\
\hline$\# 1$ & 279,676 & $\mathrm{TI}=\left(\mathrm{CO}_{2}\right.$ OR carbon OR carbon dioxide $)$ \\
\hline$\# 2$ & 32,772 & $\begin{array}{l}\mathrm{TI}=\text { (sequestration OR storage OR capture OR } \\
\text { utilization OR use }) \text { AND \#1 }\end{array}$ \\
\hline$\# 3$ & 4558 & $\begin{array}{l}\mathrm{TI}=(\text { trends OR develop* OR review* OR } \\
\text { technolog* OR production OR assess* OR } \\
\text { progress OR evolution OR study) AND \#2 }\end{array}$ \\
& & $\begin{array}{l}\mathrm{TS}=(\text { environment* OR climate OR improv* OR } \\
\text { polic* OR sustain* OR renewable) AND \#3 }\end{array}$ \\
\hline$\# 4$ & 1398 &
\end{tabular}

Figure 4. Statistics of the carbon research articles.

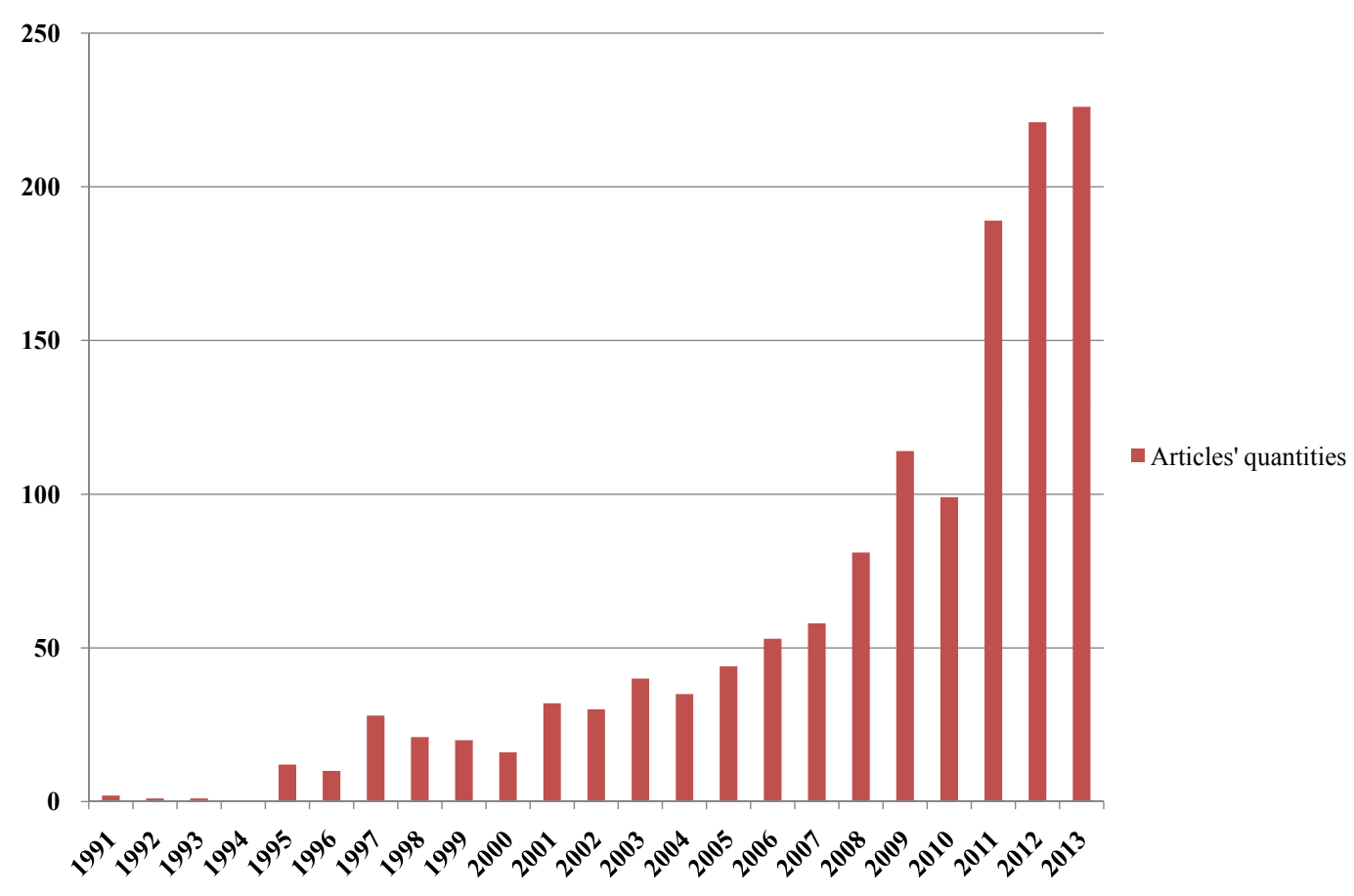

\subsection{Mapping the Network Diagram}

We entered the final result of the DAS into NodeXL, which constructed a keywords-publication date network diagram. Because the software initially presented us with a disordered diagram, it was necessary to arrange all of the nodes and edges, so as to elucidate the linkages between them. By changing the keywords' degree, we ensured that the figure was clean and readable. The complete handling and mapping processes are shown in Figure 5. Through this thorough and systematic analysis, a wide variety of carbon research activities on capture, storage and utilization were identified. 
Figure 5. The handling process of the network diagram for the technical research of carbon.
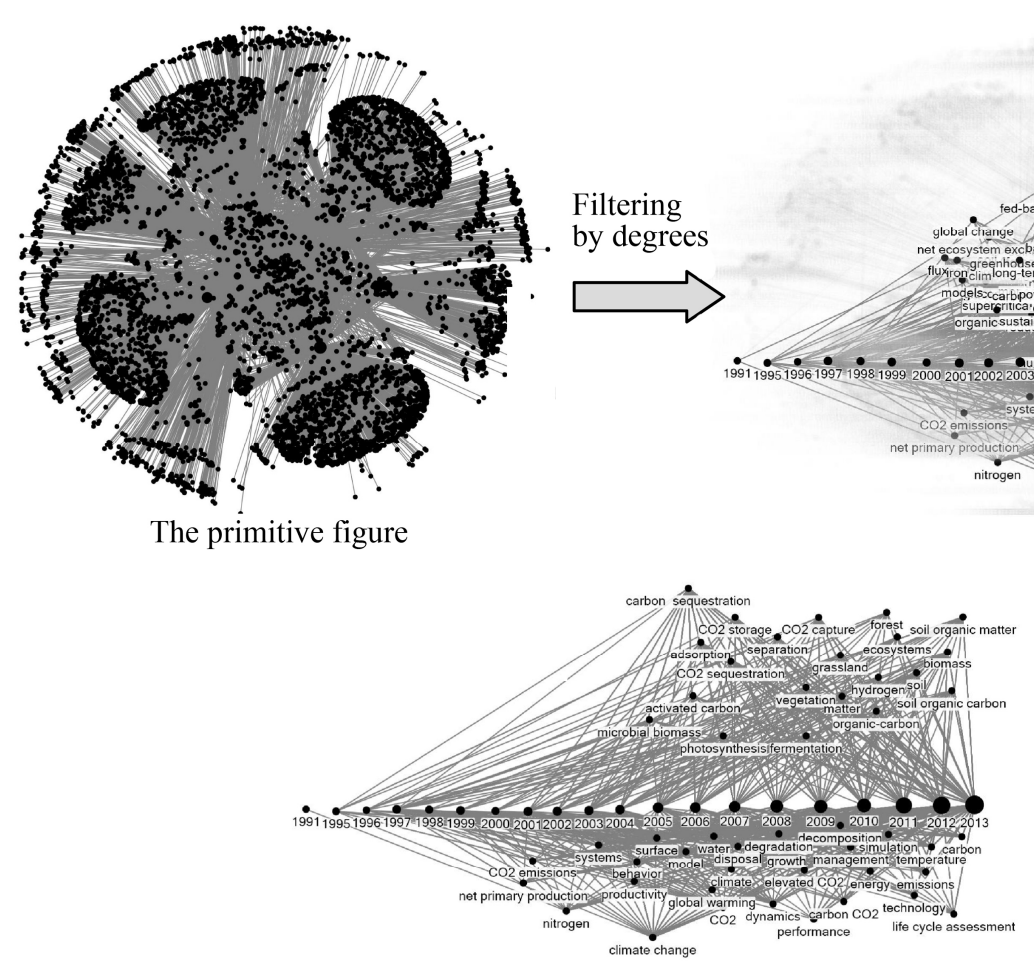

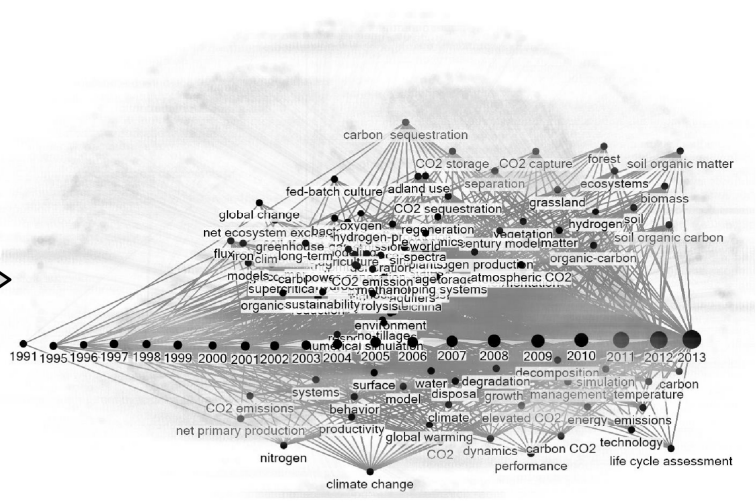

The processing figure

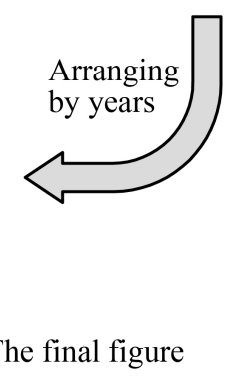

\subsection{Identifying Development and Prediction Trends}

The network diagram shown in Figure 6 can be primarily divided into two groups; carbon sequestration technologies (Area A) and BECCS (Area B). Area A focuses on carbon capture and sequestration (CCS). The most widely researched focus with 317 articles was $\mathrm{CO}_{2}$ sequestration, which belongs to storage technologies, whereas there were 150 articles that examined $\mathrm{CO}_{2}$ capture. For Area B, there were over 230 articles in total with 120 articles of these specifically examining bioenergy, such as biomass, biofuels, forests and ecosystems, and 110 papers focusing on soil organic matter issues, such as soil carbon and land use. Areas A and B are both representative of potential future trends. From the publication dates, we can conclude that carbon sequestration (Area A) has had a technological transition that has incorporated carbon capture and carbon storage. BECCS, as one of higher phases of the techno-paradigm, shows that carbon capture, utilization and storage (CCUS) technologies have been progressively commercialized, and in Area $C$ the ultimate $R \& D$ goals for carbon control from 1991 to 2013, which incorporates central topics, such as climate change, $\mathrm{CO}_{2}$ emissions and life cycle management, are clearly shown. 
Figure 6. Keywords focus trend of geothermal energy utilization.
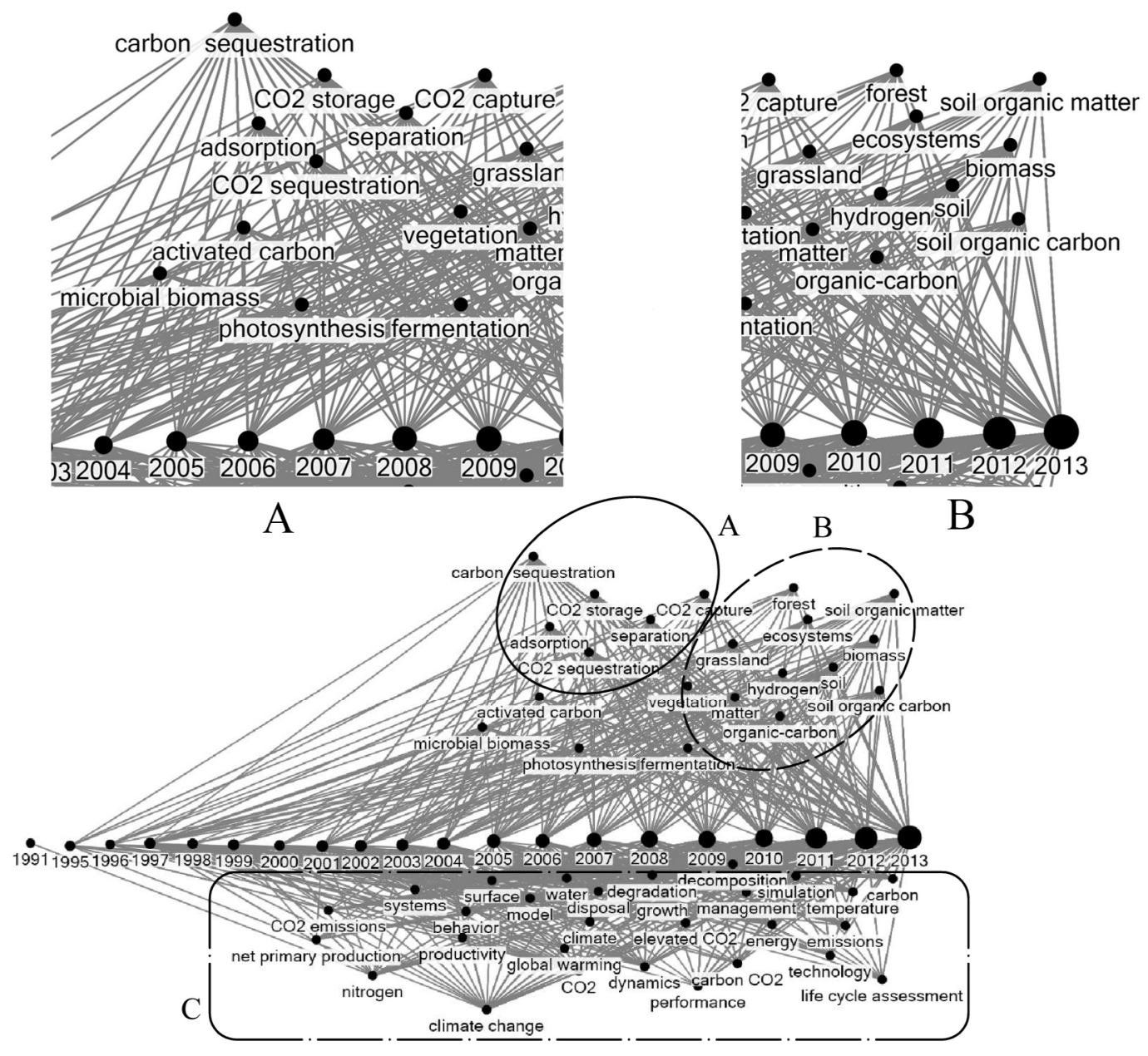

\section{Techno-Paradigm for CCS}

In spite of the rapid growth in carbon control research published worldwide, there is not a definitive or feasible theoretical framework, or a techno-paradigm, which can guide investors and funding agencies to efficiently distribute R\&D funding. Further, the presence of a techno-paradigm is extremely essential to those policy-makers devoted to reducing the effects of global warming. Any techno-paradigm should demonstrate the complete life cycle of a technological development and therefore should include sprouting (competition), evolution (diffusion) and dying out (shift) phases. From the analysis above, it can be concluded that carbon abatement measures research has mainly focused on CCS and bioenergy with carbon capture and storage. Based on the results, the development of carbon management technologies also abides by the techno-paradigm rule. Here, we propose a carbon capture and storage techno-paradigm (CCSTP) and use it to predict and guide the evolution and direction of CCS technological development. CCSTP is primarily composed of CCSTP competition (carbon capture), diffusion (carbon storage) and shift (CCUS and BECCS). The first stage is competition-oriented, which involves the development of carbon capture technologies. CCSTP diffusion refers to all processes for carbon sequestration, and CCSTP shift is mainly related to carbon utilization and bioenergy based on carbon capture and storage applications. 


\subsection{CCSTP Competition}

As awareness grows about the seriousness of global environmental problems, $\mathrm{CO}_{2}$ capture technologies have become increasingly attractive, resulting in a rise in investments in this area, thus creating the conditions for CCSTP competition. Marchetti [2] first proposed the concept of "carbon collection" in 1977. Consequently, as shown in Figures 7 and 8, a number of different $\mathrm{CO}_{2}$ capture technological trajectories were developed: (1) pre-combustion; (2) post-combustion separation; (3) oxy-fuel combustion; and (4) chemical-looping combustion [36,37]. It is well known that $\mathrm{CO}_{2}$ emissions abatement in power generation flue gas is heavily dependent on the first three methods, an issue which is addressed in Gibbins and Chalmers [38], Jordal et al. [39], Olajire [40]. Chemical-looping combustion, on the other hand, offers a possibility for the elimination of the energy intensive $\mathrm{CO}_{2}$ separation and reduces $\mathrm{CO}_{2}$ sequestration costs [41]. These four trajectories based on $\mathrm{CO}_{2}$ separation mechanisms, as the backbone of the paradigm, must contend with each other in the CCSTP competition phase.

The four classic carbon capture methodologies discussed above have their own advantages in the CCSTP competition stage. Depending on the type of fuel, these $\mathrm{CO}_{2}$ capture technologies have differing levels of performance. Pre-combustion capture is suitable for an integrated gasification combined cycle (IGCC), of which biomass and natural gas are examples [40]. Theoretically, IGCC technology is probably the cheapest option and the most promising route for $\mathrm{CO}_{2}$ capture [42]. Post-combustion capture involves separating $\mathrm{CO}_{2}$ from the flue gas mixture of power plants or some point sources and generally operates at a low pressure (1 bar) and at a low $\mathrm{CO}_{2}$ concentration (3\%-20\%) [43]. Based on available commercial technologies, coal plants are best for the deployment of post-combustion capture. Oxy-fuel combustion primarily deals with a mixture of oxygen $(>95 \%)$ and recycled flue gas instead of air in conventional plants, and as a result, relatively pure $\mathrm{CO}_{2}$ can be easily captured by cooling and compression without further separation [36]. Based on the distinctive characteristic of a near-zero emission in flue gases, both new pulverized coal-fired power plants and reformed existing plants are optimal places for oxy-fuel combustion capture [36].

Pre-combustion, post-combustion and oxy-fuel combustion capture technologies may become viable options for GHG emissions minimization. However, these technologies are all energy-intensive alternatives, which tend toward a dramatic decline in overall combustion efficiency and an increase in electricity prices. With this in mind, chemical-looping combustion (CLC), originally proposed by Richter and Knoche [44], has the potential to be a more efficient means to increase the net power efficiency and for $\mathrm{CO}_{2}$ separation [45]. As CLC does not have any enthalpy gains, it has the distinct advantage of reducing $\mathrm{NO}_{x}$ formation and separating $\mathrm{CO}_{2}$ and $\mathrm{H}_{2} \mathrm{O}$ from the flue gases [46]. Besides these advantages, a suitable oxygen carrier plays a critical role in reducing total costs.

Therefore, in the short term, by modifying flue gas processing facilities, post-combustion technology is a suitable technology, especially for power plants using amine solvents [40]. Pre-combustion technology, however, can really only be applied to new plants, but the separation of $\mathrm{CO}_{2}$ is an easier process than in post-combustion processes. Oxy-combustion, however, may be a better option than post-combustion for coal based power plants as there is less reduction in power efficiency, which would enhance $\mathrm{CO}_{2}$ capture investment [47]. In this way, oxy-combustion technology could be used 
in existing plants by retrofitting the combustion systems [39]. Although CLC has the significant advantage of reducing both the energy intensity of $\mathrm{CO}_{2}$ separation and $\mathrm{CO}_{2}$ storage costs, more research which focuses on specific process configurations and reactor designs needs to be done for this process to be commercially viable on a large scale [48]. Apart from the low efficiency and energy losses currently being experienced, power plants with $\mathrm{CO}_{2}$ capture are technically feasible and have positive environmental effects [11]. Carbon capture technological reliability, stability and separation efficiency are the biggest challenges facing the world [49]. In the evolutionary CCSTP competition process, there are many emerging technologies that will contribute to a renewable energy framework in the near future, but overall costs and technical barriers need to be overcome for these to be truly feasible options.

Figure 7. Three main technological trajectories on CCSTP competition.

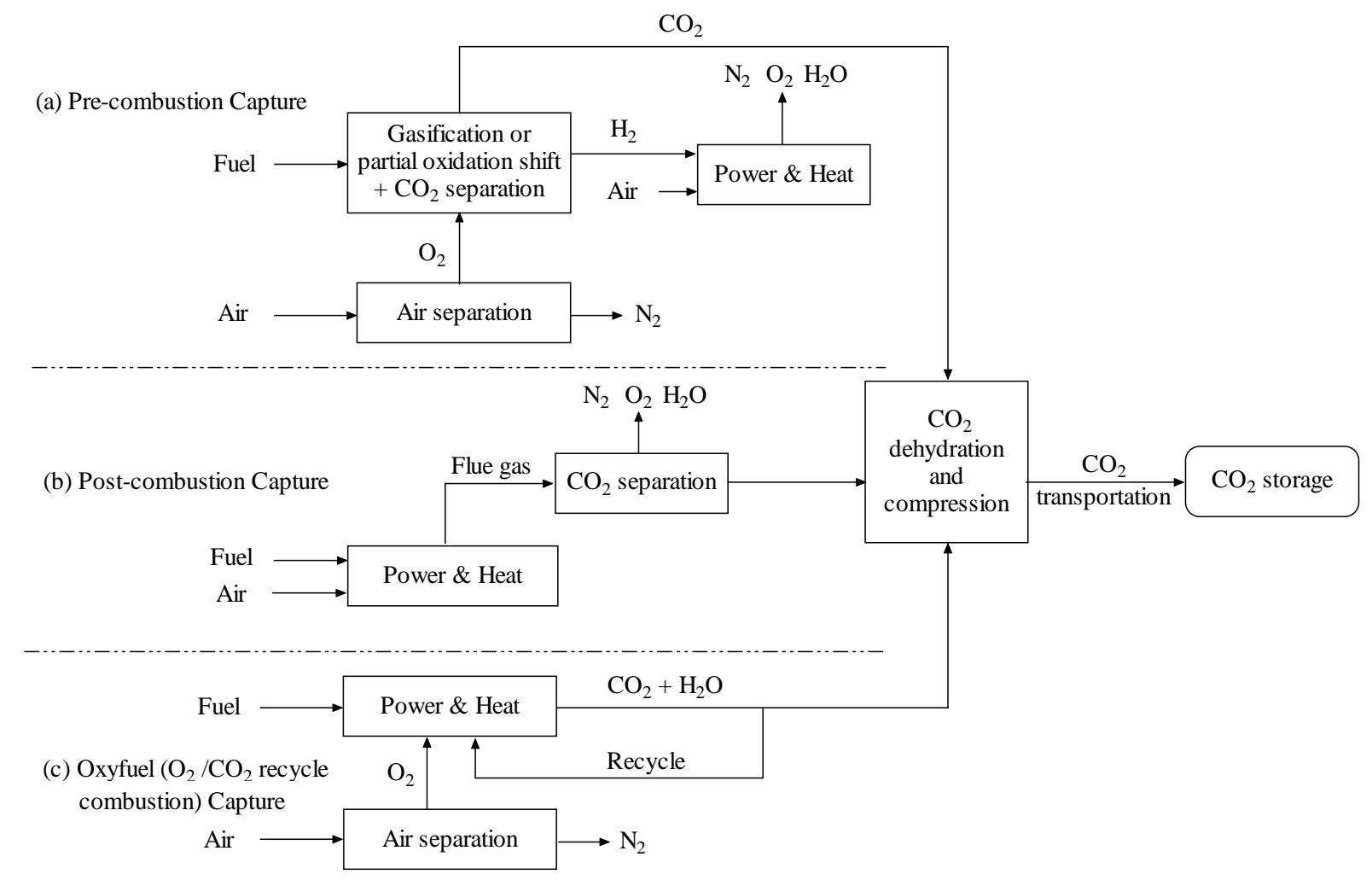

Figure 8. The chemical-looping combustion schematic.

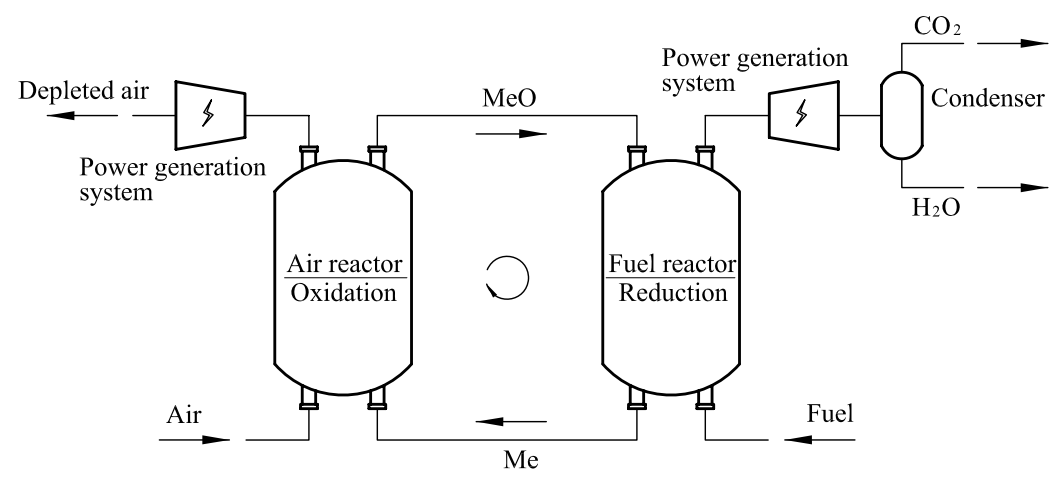




\subsection{CCSTP Diffusion}

In terms of the paradigm evolution, the most important features of these common technical innovations usually evolves during the diffusion phase [50]. Because of market demand and industrial competition, the diffusion phase gradually emerges with the dominant design being a combination of technical requirements and market demand, which can be likened to an epidemic contagion process [51]. Nagamatsu et al. [50] proposed that present technological diffusion could be divided into approximately three categories: (1) multi-generational technologies that coexist and mutually compete; (2) current technologies that are replaced by a dominant technology; and (3) innovative diffusion.

Along with the paradigm development law previously mentioned, CCSTP evolves to the diffusion phase; namely the development of carbon control from carbon capture to carbon storage. This is the stage where $\mathrm{CO}_{2}$ capture from large emission sources is permanently compressed and transported to suitable sites for sequestration as carbon sinks, instead of being released into the atmosphere, the procedure for which is shown in Figure 9.

When selecting suitable $\mathrm{CO}_{2}$ sequestration sites, monitoring, verification and risk assessments need to be taken into consideration. The study of Bachu [52] indicated that safe $\mathrm{CO}_{2}$ storage should conform to rules, such as having a potential inventory, the conduct of adaptability analyses and risk assessments and the development of surface criteria. Other requirements, such as an environmentally-friendly impact, low cost and conformation to national and international laws also need to be taken into consideration. Although the principle of the trajectories is slightly different, the kernel of the diffusion paradigm is basically the same. At present, there are two main approaches to $\mathrm{CO}_{2}$ storage; underground geological sequestration and ocean storage. The former's potential sites are primarily coal beds and mines, oil and gas reservoirs and saline aquifers, as shown in Figure 10 [48]. It is estimated that the $\mathrm{CO}_{2}$ sequestration potential of oil and gas reservoirs worldwide is between 400-900 Gt, which could increase by $25 \%$ through the addition of undetected reservoirs [12]. Compared with the several thousand GtC of storage capacity in geological storage, there is much less in ocean storage [15]. Ocean storage has its own advantages, but there are some potentially significant environmental risks, such as deep ocean acidification and low oxygen concentration regional expansion [53]. Many global and regional treaties, such as the Oslo and Paris Conventions (OSPAR), the London Convention and others, do limit or prohibit $\mathrm{CO}_{2}$ storage in the ocean to some extent. Taking into account the effectiveness and impact uncertainties, ocean storage technologies are in the initial stage of research, and so, they attract less interest from commercial enterprises. On the contrary, geological sequestration has an advantage over other trajectories because of its technical feasibility and availability, and it has the ability to reduce anthropogenic $\mathrm{CO}_{2}$ to efficiently combat climate change [52].

$\mathrm{CO}_{2}$ geological storage is perceived to be one of the most promising solutions to a noticeable reduction in $\mathrm{CO}_{2}$ emissions in the short term, but the possibility of leakage is a major barrier. Further, it would take centuries to trap $\mathrm{CO}_{2}$ permanently using geological storage. Under these circumstances, it would be possible for the deep sea to be a safer $\mathrm{CO}_{2}$ storage place. This idea was first proposed by Marchetti [2], who suggested a direct ocean disposal of $\mathrm{CO}_{2}$ by injecting gaseous, liquid or solid $\mathrm{CO}_{2}$ into ocean waters. From existing science and technology, there are two primary approaches to $\mathrm{CO}_{2}$ ocean disposal, as shown in Figure 11. The first method involves $\mathrm{CO}_{2}$ dissolution by injecting it approximately 
$1500 \mathrm{~m}$ below sea level (at pressures above 50 bars), so that the liquid $\mathrm{CO}_{2}$ mixes with the seawater. The resulting solution reaches a higher density than that of the seawater, and the liquid $\mathrm{CO}_{2} \operatorname{sinks}$. In an alternative method, $\mathrm{CO}_{2}$ is injected $3000 \mathrm{~m}$ below sea level, where an absolute pressure can be achieved to form liquid $\mathrm{CO}_{2}$, the density of which is far higher than that of seawater [54]. A more promising recent program is for liquid $\mathrm{CO}_{2}$ to be injected into depths between 1000 and $1500 \mathrm{~m}$ through a fixed pipeline or a towed pipeline. At the same time, relatively pure $\mathrm{CO}_{2}$ could be injected into the deep ocean to form hydrates in the sediment or ice-like solids, thus creating " $\mathrm{CO}_{2}$ lakes" in the depths of the sea [48].

Figure 9. Technical trajectories of the $\mathrm{CO}_{2}$ diffusion techno-paradigm.

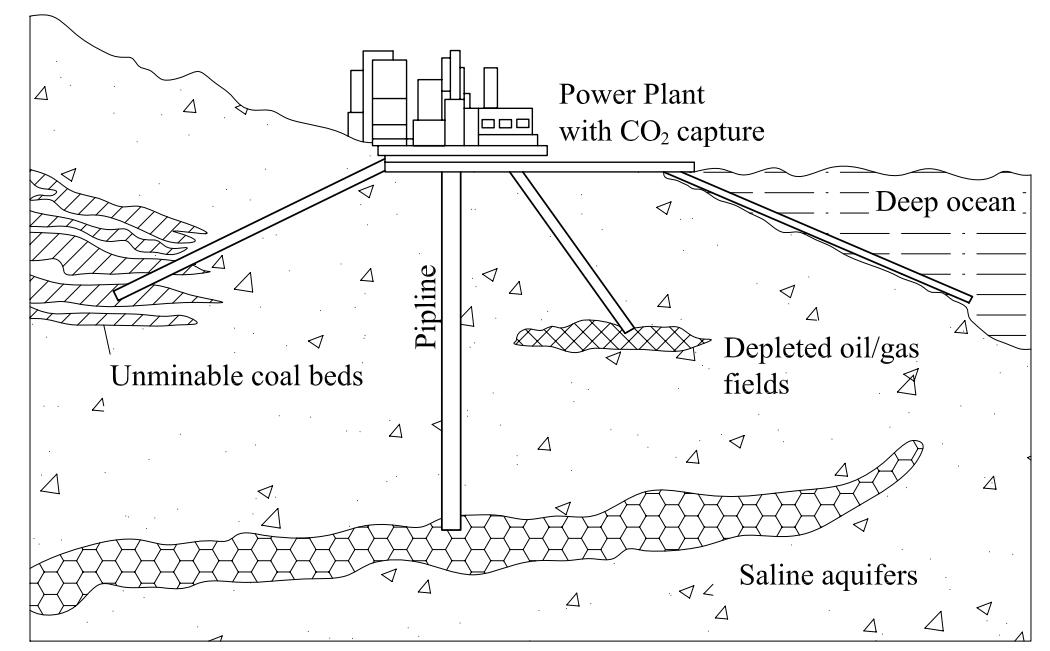

Figure 10. $\mathrm{CO}_{2}$ sequestration schematic diagram.

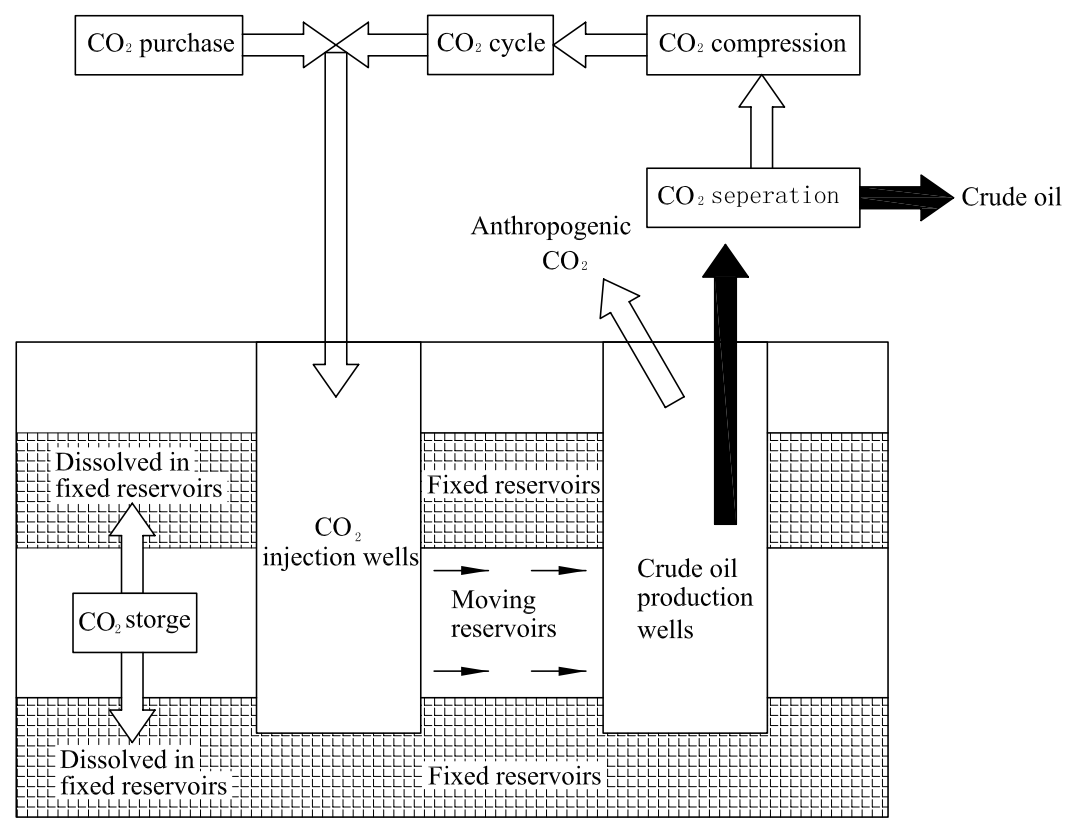


Figure 11. $\mathrm{CO}_{2}$ storage in a deep sea schematic diagram.

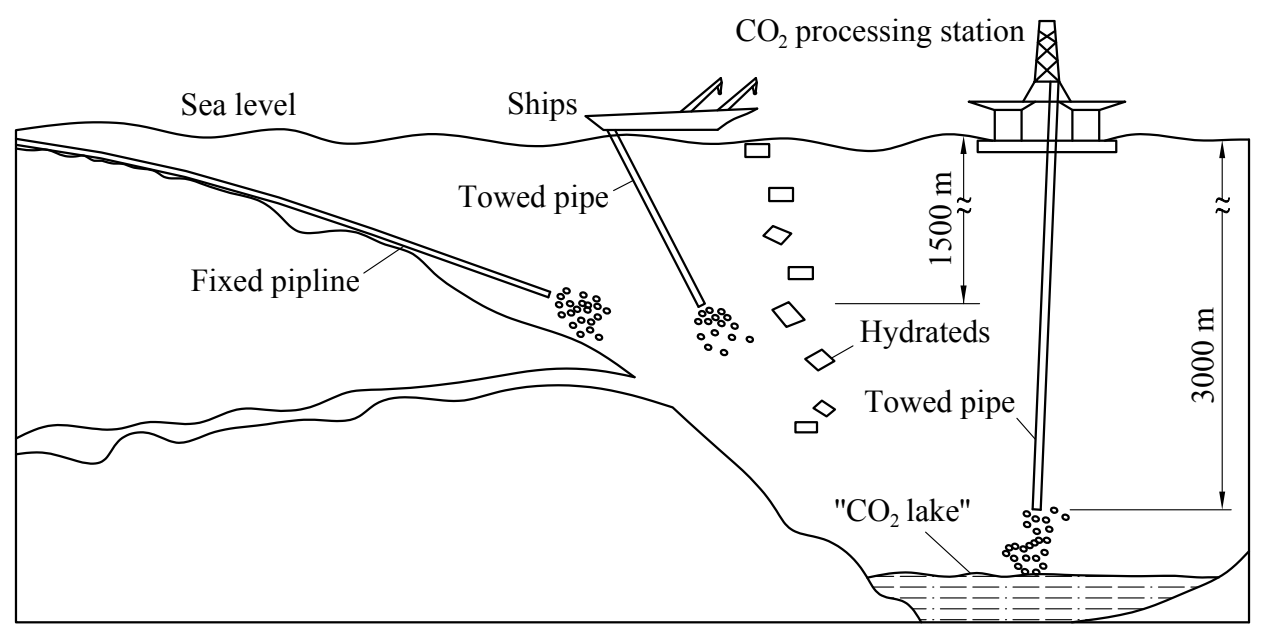

As a non-permanent reservoir, ocean storage has played a positive role. In the IPCC-WG1 meeting in 2013, the ocean is still listed as one of the "carbon dioxide removal (CDR)" methods [53]. In the near future, it could become a benign "carbon sink", provided that the prominent ocean fertilization technologies and the application of ground silicates in to the ocean become commercialized [15]. These novel technologies could avoid the hazards of direct ocean injection and the possible negative impact on marine ecosystems. Therefore, ocean storage is not currently a feasible trajectory for mitigating $\mathrm{CO}_{2}$ concentration.

Several carbon sequestration technologies have emerged as potential methods to mitigate the rising concentrations of $\mathrm{CO}_{2}$ in the atmosphere [55]. Given the possibility of accidental leakages, mineral carbonation could be one of the safest CCS alternatives compared to geological and ocean storage [56]. Mineral carbonation is a process whereby carbonate minerals are formed in a relatively steady state through the reaction of alkaline earth metals with $\mathrm{CO}_{2}$ [55]. The IPCC estimates that a power plant equipped with mineral carbonation would need $60 \%$ to $180 \%$ more energy than one without CCS. Though mineral carbonation's costs are currently higher than those for geological storage, it is still deemed advantageous, because not only is there a ready availability of the raw material, but also, this method has a benign environmental effect [12].

Lackner et al. [57] first proposed mineral carbonation as a safe, permanent $\mathrm{CO}_{2}$ disposal method. The core of mineral carbonation technology is that the gaseous $\mathrm{CO}_{2}$ is converted into geologically stable carbonates using abundant raw materials. Further, the resulting carbonates have a lower energy state than the $\mathrm{CO}_{2}$, so mineral carbonation is thermodynamically favorable and naturally occurring. Advanced chemical approaches to $\mathrm{CO}_{2}$ sequestration could allow gaseous $\mathrm{CO}_{2}$ to be transferred into an inert, stable and long-lived solid material, which would minimize the possibility of $\mathrm{CO}_{2}$ leakage. Another potential benefit is its exothermic reaction process as the exothermic heat energy from the production process can be recovered and used in other energy consuming areas of the carbonation plant [58]. At present time, there are two primary mineral carbonation methods, direct carbonation and aqueous processes, neither of which are commercially feasible. However, it is vital to research this area for use in power plants or other industrial processes in the future [12]. 
In summary, the capacity offered by various $\mathrm{CO}_{2}$ disposal sites is very significant at the CCSTP diffusion stage. Nevertheless, there are still considerable uncertainties in determining the actual capacity of these sites. Compared to other possible storage sites, even though deep ocean disposal provides the largest $\mathrm{CO}_{2}$ storage capacity, it could possibly be fatal to deep ocean marine life environments if leakage occurs [54]. Therefore, it is necessary to conduct a comprehensive risk assessment before the deep ocean disposal implementation of large-scale $\mathrm{CO}_{2}$. Not only could potable water be possibly contaminated by the $\mathrm{CO}_{2}$, natural occurrences, such as earthquakes and volcanic eruptions, which cannot be controlled by humans, could also threaten $\mathrm{CO}_{2}$ storage, because they could lead to sudden underground leakages [48]. It should be noted that marine geo-engineering, including ocean fertilization, is overseen and controlled by many international conventions, except legitimate scientific research [15]. Secure storage verification and monitoring are the key areas to be developed [14]. Further, while mineral carbonation and industrial utilization are suitable alternatives, the storage capacities are significantly smaller compared with the two principal methods. Such as it is, $\mathrm{CO}_{2}$ storage technologies are still appropriate trajectories at this stage of CCSTP diffusion.

\subsection{CCSTP Shift}

When techno-paradigms move into shift phase, disruptive technologies and technological limitations emerge. Disruptive technologies are a result of full competition in a specific business area, while product demand in the market is closely related to the emergence of technological limitations. Therefore, market demand and industrial technological competition are the main reasons for the paradigm shift. This also explains why this CCSTP shift stage is later than that of a conventional shift. In this way, after the CCSTP competition and diffusion phases, the CCSTP shift phase gradually builds along the paradigm development rule. Despite the increasing maturity of these two phases and the gradual commercialization, it is only in this third phase that the goal of a sustainable world can be ultimately achieved. It is believed that carbon capture, utilization and storage (CCUS) and BECCS, as appropriate solutions, may be the two vital trajectories of the CCSTP shift cornerstone.

\subsubsection{Carbon Capture, Utilization and Storage}

As integrated technologies, CCUS avoids $\mathrm{CO}_{2}$ being released into the atmosphere [59]. As a raw material, the captured anthropogenic $\mathrm{CO}_{2}$ may make a possible contribution towards industrial and commercial processes, including such areas as the food industry, the chemical industry and the oil industry. Carbonated soft beverages and soda water are the main uses for $\mathrm{CO}_{2}$ in the food industry. Besides these, dry ice, a solid form of $\mathrm{CO}_{2}$, is also widely used to cool grapes quickly in the wine making process, as well as to freeze foods, such as ice cream, for transportation and storage. In industrial production processes, $\mathrm{CO}_{2}$ is mainly employed in the form of compressed air for pneumatic tools, pipeline purging and pressure testing and as a protective gas for welding, due to its low cost and inert gas characteristics. The former is mainly used for pneumatic tools and pipeline purging and pressure testing. In addition, $\mathrm{CO}_{2}$ is also often used in fire-fighting, especially in electrical fires.

$\mathrm{CO}_{2}$ captured from the atmosphere plays an extremely vital role in the energy industry. In the coming decades, it is expected that fossil fuels will still prevail as the world's primary energy supplies. With 
this in mind, there are three dominant methodologies for the utilization of the $\mathrm{CO}_{2}$ captured from combustion flue gas and other plants; $\mathrm{CO}_{2}$ enhanced oil recovery $\left(\mathrm{CO}_{2}\right.$-EOR), $\mathrm{CO}_{2}$ enhanced gas recovery $\left(\mathrm{CO}_{2}\right.$-EGR) and $\mathrm{CO}_{2}$ enhanced coal-bed methane recovery $\left(\mathrm{CO}_{2}\right.$-ECBM) [40,60]. Because of the substantial profits gained from oil and gas production, Van Bergen et al. [61] proposed that at the beginning of $\mathrm{CO}_{2}$ utilization, these three methods should be economical, regardless of $\mathrm{CO}_{2}$ credits or taxes. Thus, these primary methods could increase the value per ton of sequestration atmospheric $\mathrm{CO}_{2}$ [61].

It is widely believed that $\mathrm{CO}_{2}$ sequestration in sedimentary rocks can make a significant contribution to the abatement of atmospheric $\mathrm{CO}_{2}$ [12]. Oil and gas fields, which have trapped buoyant fluids for millions of years, are considered secure storage sites. So far, the application of $\mathrm{CO}_{2}$-EOR in depleted reservoirs has been found to be the most popular technology, not only for reducing the amount of anthropogenic $\mathrm{CO}_{2}$, but also in boosting crude oil production [62]. Although the deposition ability in oil reservoirs is very limited over the long run, petroleum reservoirs are still the most important carbon sinks today. Similarly, obsolete natural gas fields, where $\mathrm{CO}_{2}$ could be injected, might enhance natural gas extraction. Although the development of $\mathrm{CO}_{2}-\mathrm{ECBM}$ is a later technology than $\mathrm{CO}_{2}-\mathrm{EOR}$, the many cases of $\mathrm{CO}_{2}$-ECBM demonstrate that $\mathrm{CO}_{2}$ storage in unmineable coal-beds is technically feasible [60]. However, when considering the production history, the degree of development, the gas injection conditions and the economic feasibility, not all reservoirs are suitable for $\mathrm{CO}_{2}$ storage. Storage capacity and the permeability of the reservoirs may limit oil reservoirs suitability for $\mathrm{CO}_{2}$ storage and postpone the arrival of the CCSTP shift. The EOR, EGR and ECBM $\mathrm{CO}_{2}$ storage capacities are shown in Table 3 [12].

Table 3. Capacity of $\mathrm{CO}_{2}$ storage by enhanced oil recovery (EOR), enhanced gas recovery (EGR) and enhanced coal-bed methane (ECBM).

\begin{tabular}{cc}
\hline Reservoir Types & Potential Storage Capacity $\left(\times 10^{\mathbf{9}}\right.$ Tons $\left.\mathrm{CO}_{2}\right)$ \\
\hline EOR, EGR & $675-900$ \\
ECBM & $3-200$ \\
\hline
\end{tabular}

Hovorka and Tinker [63] believed that active oil producing fields, where $\mathrm{CO}_{2}$-EOR is technically feasible, provide credible opportunities for the initiation of $\mathrm{CO}_{2}$ storage demonstration projects, as shown in Figure 12. Not only can these sequester $\mathrm{CO}_{2}$, but they can also increase crude oil production, so that the petroleum traps and seals can be an ideal option now for $\mathrm{CO}_{2}$ geological storage. In 2011, it was reported that between 270 and 1300 million barrels of oil could be recovered using $\mathrm{CO}_{2}$ for EOR in the Chinese Daqing Oil field. Even though oil has been produced using conventional extraction technologies, $\mathrm{CO}_{2}$-EOR can be readily applied [64]. Highly dense phase $\mathrm{CO}_{2}$ is injected into the oil well instead of the more traditional water injection, which may offer a higher storage capacity on account of its higher density compared to gaseous $\mathrm{CO}_{2}$ [65]. 
Figure 12. $\mathrm{CO}_{2}$-EOR system flow diagram.

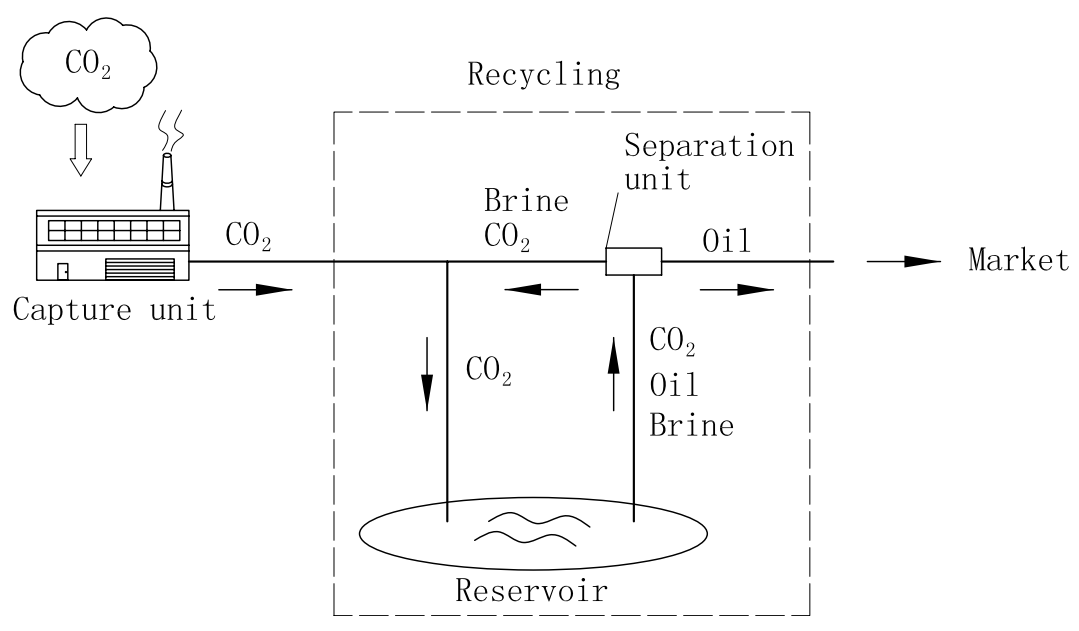

EOR with $\mathrm{CO}_{2}$ injection is also a mature technology, but the economic benefits of this process are still variable, as it is heavily dependent on oil prices and the economy [66]. There is a fundamental distinction between commercial EOR and climate policy-oriented EOR (CPO-EOR). The former currently uses mainly $\mathrm{CO}_{2}$ co-produced with natural gas, as well as naturally occurring $\mathrm{CO}_{2}$, with the main purpose being to maximize oil recovery with a minimum of $\mathrm{CO}_{2}$ injection. On the contrary, CPO-EOR use CCS technology to capture anthropogenic $\mathrm{CO}_{2}$, with the primary aim of producing oil by using and storing as much anthropogenic $\mathrm{CO}_{2}$ as possible. This is why commercial EOR operators are relatively insensitive to climate policy and much more responsive to oil-price increases than to increases in carbon taxes. However, these approaches still remain experimental and require large-scale pilots before they are disseminated widely. Before such fields can be considered as suitable for $\mathrm{CO}_{2}$ storage in terms of feasibility and cost, detailed site assessments are also necessary [67]. Decisions on how to proceed with production should be made within the next few years to conclude whether new EOR processes should be introduced.

$\mathrm{CO}_{2}$-ECBM, an increasingly important $\mathrm{GHG}$ control issue, is regarded as one of the possible approaches to mitigate the ever-increasing anthropogenic $\mathrm{CO}_{2}$ concentrations and to boost $\mathrm{CH}_{4}$ recovery, as shown in Figure 13. $\mathrm{CO}_{2}$-ECBM, with a fine network of injection and production wells, could enhance coalbed methane recovery and provide a satisfactory solution to the permanent storage of $\mathrm{CO}_{2}[64,65]$, which could not only reduce initial costs, but also raise methane production [68]. Adsorption is the main trapping mechanism used for $\mathrm{CO}_{2}$ storage in coal seams, accounting for over $95 \%$ of total storage. Both the gas trapped in the matrix structure and the captured $\mathrm{CO}_{2}$ dissolved in the pore water are trapped [65]. However, only a few ECBM field tests have shown that the $\mathrm{CO}_{2} / \mathrm{CH}_{4}$ displacement mechanism is actually effective. The most promising ECBM cases can be found in China, Europe, Canada, Japan, Australia and Indonesia. China, especially, has demonstrated a high techno-economic potential for ECBM projects [64], but these have not yet been commercially proven. This further exposes the importance of government subsidies and public welfare sector investment. 
Figure 13. ECBM conceptual model.

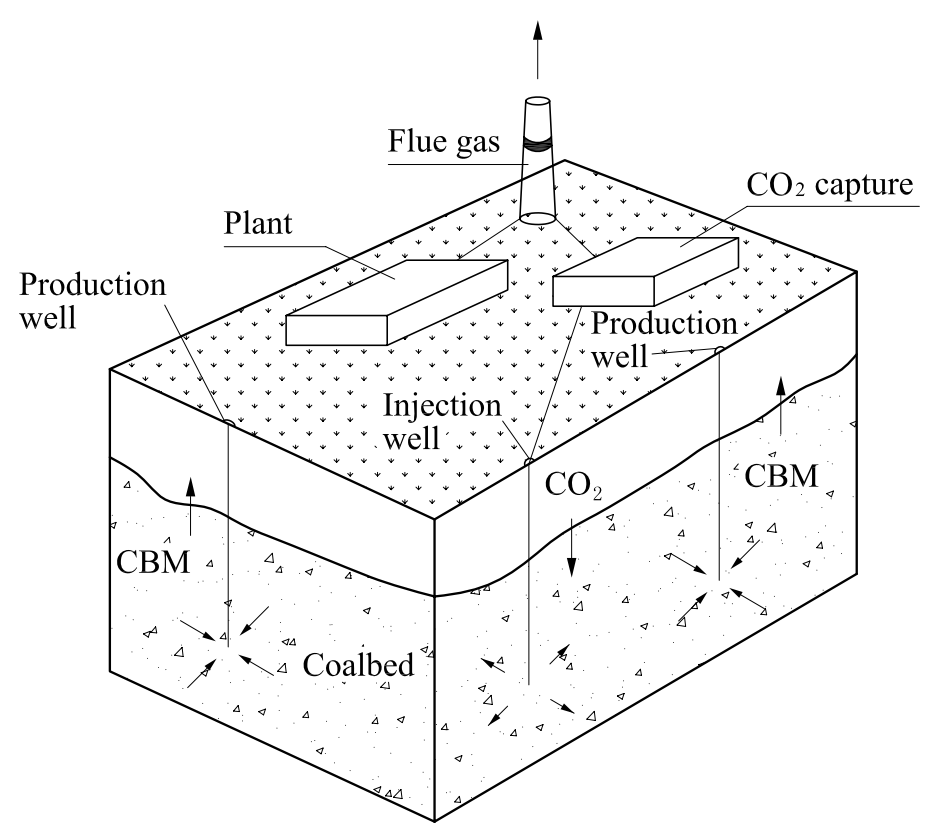

\subsubsection{Bioenergy with Carbon Capture and Storage}

There are many mitigation scenarios to reduce the growth of the anthropogenic $\mathrm{CO}_{2}$ concentrations by 2100. However, faced with stringent GHG control policies, BECCS is a more rapid and effective approach to reduce $\mathrm{CO}_{2}$ emissions in the long term. In Figure 6, it can be seen from the literature mining that BECCS has been a dominant research focus around the world. In the IPCC-AR5-WG3, large-scale BECCS could have a significant mitigation potential, resulting in decreases of 430 to $480 \mathrm{ppm} \mathrm{CO}_{2}$ by 2100 [15,69-71]. As shown in Figure 14, it can be concluded that, while the use of CCS can meet most concentration targets, BECCS can play a more significant role in meeting lower stabilization targets at lower costs [72]. BECCS is able to remove atmospheric $\mathrm{CO}_{2}$ and meet energy demands through the delivery of power and heat with net negative emissions [73]. Bioenergy production from agricultural and forestry resources is absolutely necessary, not only to mitigate climate change, but also to ensure supply security. The application of BECCS is a compromise between fossil fuel alternatives and GHG emissions control [74]. As biomass is both an important carbon sink and a substitute for fossil-fuels, it is worthwhile to focus on the $\mathrm{CO}_{2}$ balance in bio-energy systems with $\mathrm{CO}_{2}$ capture and storage [75].

Rhodes and Keith [76] proposed that gasification, post-combustion capture and oxy-fuel combustion with $\mathrm{CO}_{2}$ capture, make it possible to apply CCS to biomass for the production of electricity, hydrogen and liquid biofuels and for use in power plants, combined heat and power plants and in flue gas streams from the pulp industry. As shown in Figure 15, compared to conventional CCS with near-zero emissions, BECCS can achieve negative emissions because of the permanent $\mathrm{CO}_{2}$ geological sequestration and sustainable biomass harvesting practices during its growth [73,77,78]. If the $\mathrm{CO}_{2}$ emitted within the closed cycle were to be captured and permanently stored, it could achieve net zero or even negative emissions. As biomass is sustainable because the $\mathrm{CO}_{2}$ from biomass combustion or transformation is neutral, BECCS can make a significant contribution to a net removal of anthropogenic $\mathrm{CO}_{2}$ emissions 
worldwide [79]. Table 4 shows a schematic representation that compares the lifecycle emissions of conventional CCS and BECCS, as well as highlighting the conceptual differences between them [12].

Figure 14. Radar map of the projected cost analysis.

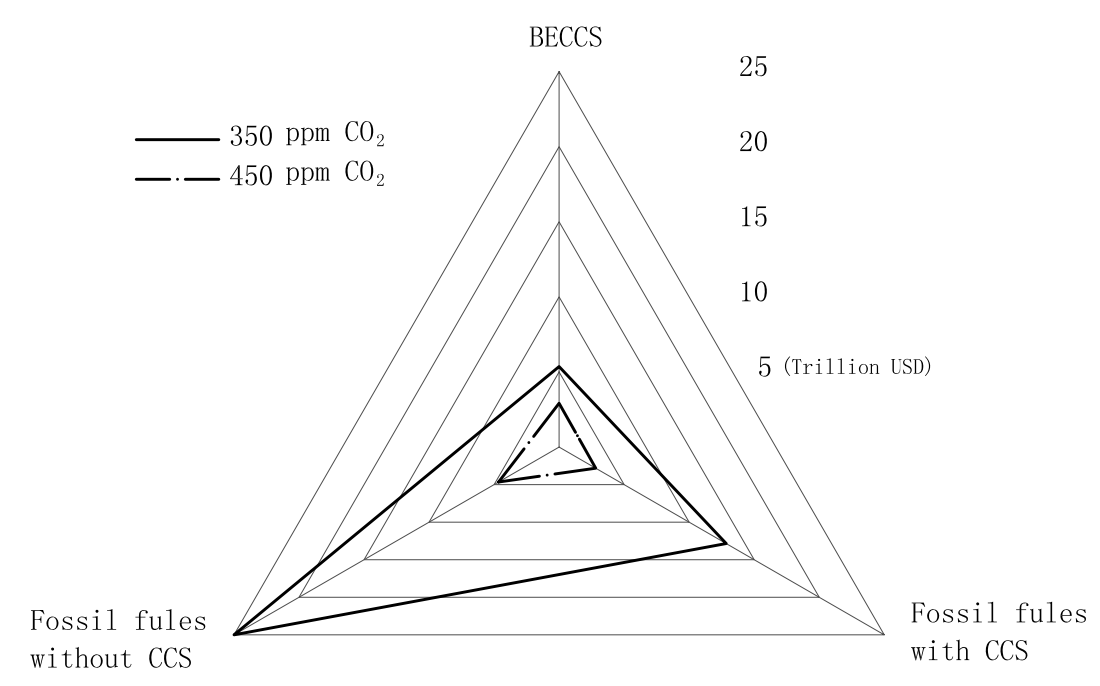

Figure 15. Comparison of bioenergy with CCS (BECCS) and conventional fossil fuel combustion.

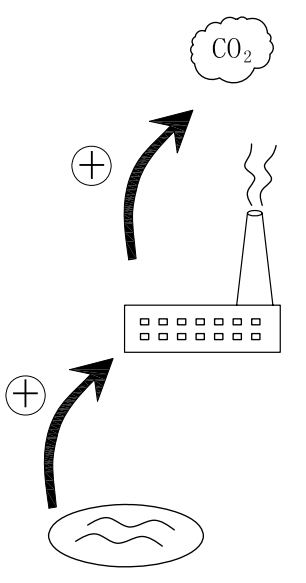

Conventional fossil fuel combustion

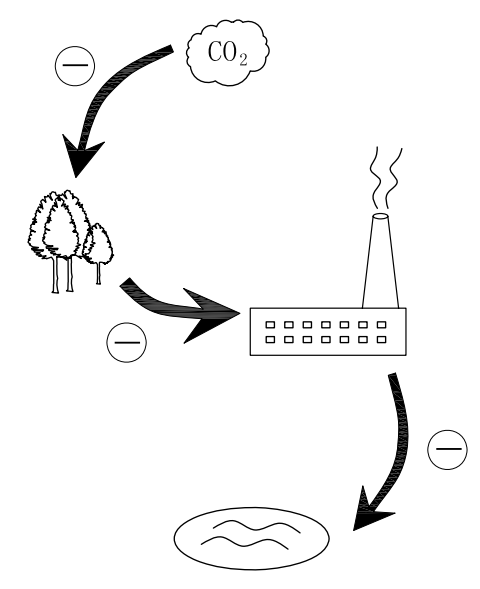

BECCS

Table 4. Comparing lifecycle emissions of conventional CCS and BECCS.

\begin{tabular}{ccc}
\hline Phase name & Biomass Energy with CCS & Conventional CCS \\
\hline Biological sequestration & -1 & - \\
Fuel transformation & 1 & 1 \\
Capture and storage & -1 & -1 \\
Lifecycle emissions & -1 & 0 \\
\hline
\end{tabular}

According to Obersteiner et al. [80], BECCS not only removes carbon from the natural carbon cycle, but it also provides low-carbon energy products through combustion and photosynthesis. Because this is 
likely to significantly reduce the mitigation costs of $\mathrm{CO}_{2}$ in the atmosphere, it is destined to become one of the future energy mixes [79]. However, as BECCS also has specific regional compatibilities, some countries and regions will be more suitable for large BECCS applications than others. For example, Sweden is well placed for bio-energy plants in the processing industry, has access to offshore storage sites and, thus, would be able to maintain relatively low power sector emissions [75]. On the contrary, bio-energy resources in the U.K. are relatively small, so BECCS would probably be designed to be co-firing rather than a dedicated biomass system. This means that establishing smaller scale biofuel plants adjacent to existing $\mathrm{CO}_{2}$ transport and storage infrastructure would maximize their performance.

As this paper has mentioned, the CCSTP evolution is slower than that of ordinary commercial paradigms. One of the main reasons is the need for additional incentives to encourage biological sequestration, capture or storage. Providing a safe solution for long-term $\mathrm{CO}_{2}$ storage, $\mathrm{BECCS}$ can give leverage to the carbon-reduction potential of the world's biomass resources. The advantage for policy makers of providing these extra incentives at capture is that they can use the same basic administrative infrastructure. However, some countries may wish to put the BECCS incentive into biological sequestration if this fits better with their biomass policies. BECCS has not been economically viable, because environmental taxes have only concentrated on conventional environmental policy instruments, which is a key issue for researchers. Moreover, the regulations providing guidance for GHG reduction in the Kyoto framework do not consider BECCS eligible for the first commitment period of the protocol [81]. As a result, there are still no incentives for governments and firms to capture $\mathrm{CO}_{2}$ from biomass. To overcome this barrier, it is strongly recommended that a compromise policy based on a carbon tax and a subsidy for BECCS be considered. Specific subsidies for emissions reductions are important to stimulate the technological development of CCS and BECCS [79].

To summarize, the effective utilization of GHG emissions, particularly $\mathrm{CO}_{2}$, presents both a serious challenge and a major opportunity for sustainable development. Different fuels, materials or even chemicals can be synthesized using $\mathrm{CO}_{2}$, therefore $\mathrm{CO}_{2}$ utilization can contribute to enhancing sustainability. In this way, when renewable sources of energy are used as a basic energy, their use should be focused on long-term sustainability [82]. On the other hand, negative $\mathrm{CO}_{2}$ emissions through the implementation of BECCS could give leverage to the carbon-reduction potential of the world's biomass resources [75]. Nowadays, CCS is still a viable alternative for the abatement of $\mathrm{CO}_{2}$ concentrations, although it is not theoretically the best choice. BECCS is recognized as a benign and low risk solution with negative emissions characteristics in the long run [83]. As silver bullets, these two alternatives, in the CCSTP shift phase, offer a unique opportunity for a net removal of anthropogenic $\mathrm{CO}_{2}$ while fulfilling energy needs, which is the future hope of the global renewable energy consumption structure.

\section{Analysis and Discussion}

The major distinctions between the CCS techno-paradigm and the conventional commercialized techno-paradigm are political barriers and public acceptance. Profit maximization is the fundamental driving force in this age of rapid economic development. Pearson and Foxon [17] argue that a characteristic of the CCS methodologies is that in the early stages, they are not generally competitive, except in specific industrial fields, and will remain so until learning curves fall, unit costs reduce, 
production scales rise and experience is accumulated. From the perspective of techno-paradigm development, the CCS techno-paradigm is different from others, as shown in Figure 16. In the competition stage, as the deployment of CCS has little financial benefit [14], the private sector is still unlikely to invest, because the cost of abatement is higher than current carbon prices. In the absence of urgent environmental pressures, governments are only willing to provide funding for research into a few CCS technologies. As a result, development is seriously impeded in the competition stage. However, once CCS technical and political obstacles have been overcome, the costs fall dramatically, as reflected in the $\mathrm{S}$-curve. The situation of $\Delta b$ indicates this, and it is at this point that the situation changes to one where there is a greater urgency to employ CCS technologies. With regard to $\Delta c$, we can see an increase in the development speed for the different CCSTP trajectories and an urgency to apply an appropriate CCSTP. As shown in Figure 17, the private sector's willingness to invest may improve over time when CCS becomes a more competitive abatement option [84]. Incentive policies for the deployment of CCS initially focus on overcoming technical and commercial barriers, which also explains why the conventional paradigm is faster overall than CCS in the first half of the S-curve, while the opposite is true in the latter half.

Figure 16. A comparison of the conventional techno-paradigm and CCS techno-paradigm.

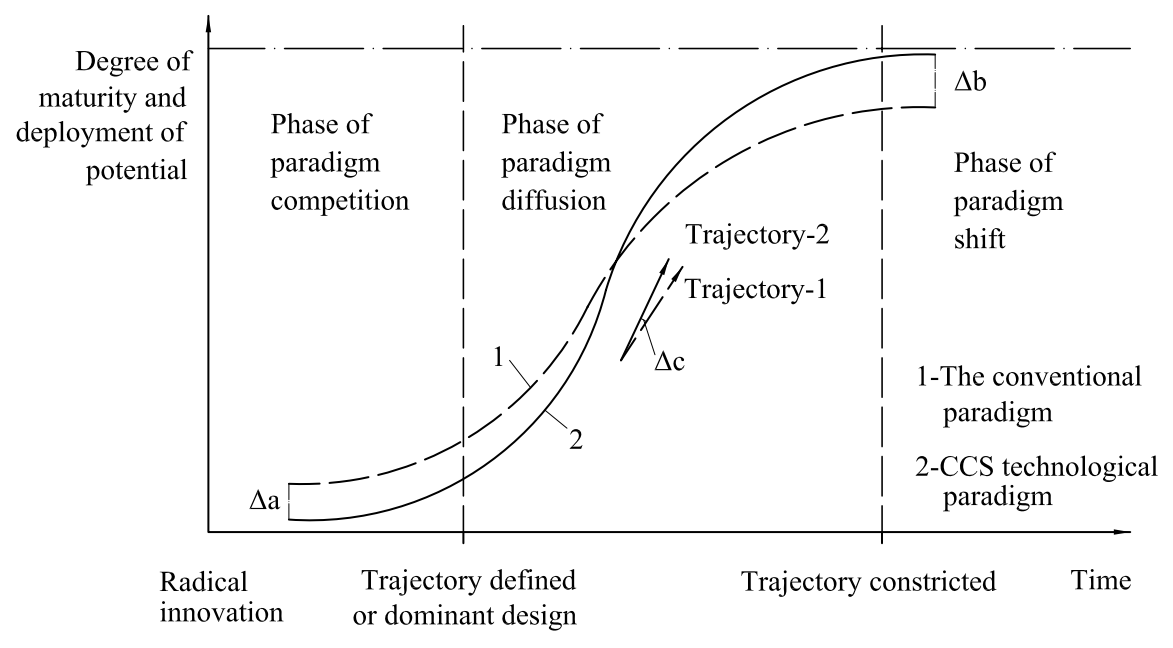

Figure 17. Development of CCS as a competitive abatement alternative.

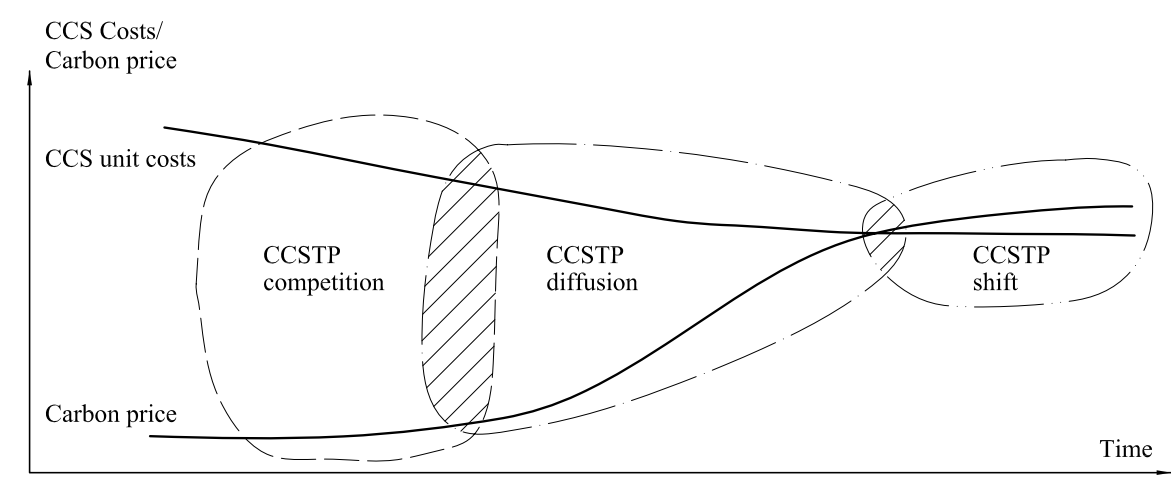

The successful implementation of any government policy is heavily reliant on public acceptance, which is even more crucial for CCS technologies. In many countries and regions, the effect of carbon 
reduction measures on environmental protection, as well as for CCS technologies has been subject to controversy and discussion since the IPCC-AR4. Few relevant policy instruments or economic instruments have been invested in the development of CCS technological and infrastructure projects. However, as climate change effects are being more widely felt, the public's attitude to CCS technologies is beginning to gradually change. Although there is a subtle divergence in the choice of the specific CCS technology trajectories and the related policies, it is generally believed that regional cooperation could offer substantial opportunities for improving the environment. Due to the effect of global environmental issues, close cooperation and mutual sharing between countries are essential for climate change mitigation, especially in the development of mutual policy frameworks, CCS infrastructure and the implementation of carbon taxes or carbon pricing schemes, as policies in isolated countries or regions have little effect. With the policy barriers gradually being overcome and public acceptance increasing, many countries and regions have begun to support carbon reduction policies and measures. Governments have begun to intensify funding towards CCS technology R\&D, as well as encouraging financial investment and subsidies in infrastructure projects, both of which are in accordance with the different mitigation scenarios. It is estimated that between 2010 and 2012, of the total climate finance of USD 343 to 385 billion per year, about $95 \%$ of this is expected to be spent on carbon reduction. At the same time, private investment funds for environmental protection are rising, contributing USD 267 to 224 billion per year from 2010 to 2012 [15]. Since private capital investment, the 20 developed and developing countries that have the most serious level of $\mathrm{CO}_{2}$ emissions have significantly reduced this by 2012. Policy instruments are widely employed in many industries closely related to the public, such as energy, transport, buildings, industry, agriculture, human settlements and infrastructure [15].

Policy instruments and economic instruments are expected to play a pivotal role in the accomplishment of global carbon reduction. The huge uncertainties, such as complexity, broad geographic coverage and a long-term presence, are the basic characteristics of these environmental problems, particularly in $\mathrm{CO}_{2}$ emissions reduction. If there are no appropriate instruments, the development of CCS technology will be seriously impeded. Despite the serious environmental issues, uncertainties and the possible large risks, this means that governments are very cautious when developing specific carbon reduction policies and economic instruments, which, in turn, seriously affects private investments.

Economic instruments are primarily made up of incentives, carbon taxes and subsidies [15]. Incentives could be the most attractive instrument for the acceleration of CCS technologies R\&D. Without adequate incentives, there would be few CCS pilot projects, pilot testing, accumulation of adequate empirical data or commercialized power plants, as CCS technology is difficult to deploy on a large scale. Carbon taxes are attractive, as they can force a change in consumption patterns and lifestyles. Furthermore, the fact that carbon taxes rely on existing tax infrastructures could also be an efficient instrument, which may encourage private investment funds to choose an appropriate CCS technology path, such as BECCS. Subsidies are a potential option for economic instruments, as they can encourage the adoption of cleaner industrial processes, such as the use of renewable energy sources. Further, subsidies can ensure that the government-selected technologies are developed as a priority. Fossil energy subsidies are a good example, the use of which has significantly reduced $\mathrm{CO}_{2}$ emission levels. 
Public policy instruments, such as emissions trading, cap-and-trade, $\mathrm{CO}_{2}$ certificates and others, have had a significant effect, increasing guaranteed mechanisms to reduce the uncertainties and the risks that private investors face, while increasing confidence. The concept of emissions trading, originally proposed in 1968 by Dales and Pollution [85], has played a role in programs, such as the Regional Clean Air Incentives Market in California (California RECLAIM) Program and the U.S. Acid Rain Program. Learning from these successful experiences, governments have developed new emissions trading schemes to mitigate GHG emissions, but the effect has not been significant yet for several reasons. The formulation of any policy depends on the institutional and political feasibility and cost-effectiveness, as well as national economic strength. In the cap-and-trade case, as the cap is closely related to the stringency of the trading scheme, an appropriate price ceiling is vital to political feasibility. A better option for the allocating of rights and appropriate caps when developing trading emissions schemes should be taken into consideration. Carbon certificates are another potential alternative that can also provide a powerful support to $\mathrm{CO}_{2}$ emissions reductions. Carbon credits and carbon markets are an important part of the carbon reduction path. In the future, the development of carbon certificates in Europe, to some extent, will affect the large-scale deployment of CCS technologies, such as BECCS. These cases show that it is not enough to rely solely on one or two policy instruments to mitigate climate change. From a development perspective, these policy instruments to control $\mathrm{CO}_{2}$ emissions can provide governments and the public with a good reference and a clear direction. It is expected that these instruments are likely to shift over time, as shown in Table 5. To achieve the mitigation $\mathrm{CO}_{2}$ emissions, most countries have begun to employ a combination of policy and economic instruments. Public acceptance should be considered as a major obstacle to address the large-scale deployment of CCS [86]. Nowadays, public acceptance of energy technologies, as well as CCS technologies is gaining increasing importance.

Table 5. CCSTP policy instruments.

\begin{tabular}{clll}
\hline No. & \multicolumn{1}{c}{ CCSTP Competition } & CCSTP Diffusion & \multicolumn{1}{c}{ CCSTP Shift } \\
\hline 1 & $\begin{array}{l}\text { Supporting capital deployment } \\
\text { and operations }\end{array}$ & $\begin{array}{l}\text { Greater willingness to invest } \\
\text { by capital markets }\end{array}$ & $\begin{array}{l}\text { Incentivizing } \\
\text { operations }\end{array}$ \\
\hline 2 & $\begin{array}{l}\text { Costs and risks shared by } \\
\text { public and private sector }\end{array}$ & $\begin{array}{l}\text { Reduced learning spill-overs and } \\
\text { better know-ledge of risks }\end{array}$ & $\begin{array}{l}\text { Costs and risks mainly } \\
\text { borne by private sector }\end{array}$ \\
\hline 3 & Special subsidizing & Polluter pays principle & Penalizing emissions \\
\hline 4 & Specific support & Technology commercialization & Technology agnostic policy \\
\hline
\end{tabular}

Apart from public acceptance, policy and economic instruments, it is essential to focus on the CCS infrastructure, including $\mathrm{CO}_{2}$ transport and storage, in order to achieve many scenarios. The implementation of large-scale CCS infrastructure, as well as CCS technologies is significant to global climate control strategies. A full CCS value chain is principally involved in $\mathrm{CO}_{2}$ capture, transport and storage. From the perspective of transport, the major hurdles are technical feasibility and cost-effectiveness based on transport distance. Due to high investment and risk, large-scale transport alternatives are impossible in CCS pilot plants, although they are much more cost-effective in the long run. The CCS value chain is substantially determined by carbon storage as an important part. Without 
massive storage capacity, large-scale CCS demonstration projects will not be feasible. Although carbon capture technologies for plant-scale $\mathrm{CO}_{2}$ separation are rapidly evolving, there are some uncertainties in choosing ideal sites of carbon storage. As an urgent priority, precise evaluation after initial exploration of large capacity storage options is vital to address the large-scale deployment of CCS on a timescale. The capacity and cost of storage sites selected, such as geologic reservoirs or others, should be regarded as fundamental problems for CCS infrastructure. Many aspects of the CCS chain will be subject to uncertainties, which incorporate storage capacity, technical feasibility, capital investment, transportation cost, risks, etc. This requires extensive large-scale CCS demonstration projects, which can provide valuable references in many aspects, such as infrastructure designing, investment analysis, risk assessment and climate strategy planning.

Continuing political support and instruments, especially for CCS post-demonstration, are crucial to make CCS pilot plants commercially attractive to public and private investors. There are over 10 large-scale CCS pilot plants, encouraged by funds, that should be made in Europe, which are nominally active, but reducing funding [87]. The positive results of capital-intensive CCS infrastructure will have a significant impact on the carbon reduction scenario in the future. The fundamental uncertainties will be gradually clarified, provided large-scale CCS infrastructures are able to prove technically viable and economically credible. It will show the stakeholder, including public and private investors, a powerful confidence. If the CCS infrastructures had benign effects, the governments would give priority to increasing capital investment and policy or economic instruments for further public support. Meanwhile, private investors will have confidence in CCS infrastructure investment. In that case, the build-operate-transfer (BOT) pattern, usually used in traditional infrastructure, is a potential alternative to attract them. Yet, it is difficult to predict the winners amongst the low-carbon technologies, as success in the long run primarily depends on the CCS maturity and the availability of alternative energy technologies. However, there is no doubt that a stable and explicit policy framework can offer flexibility to governments and some certainties to investors.

\section{Conclusions}

Literature mining was introduced to review the CCS development trends. Based on the result, this study applied paradigm theory to analyze CCSTP processes and to provide a guide for the future development direction of CCS technologies. Depending on the different maturity periods for CCS technologies, three main stages were identified; CCSTP competition, CCSTP diffusion and CCSTP shift. Because of the increasing focus on $\mathrm{CO}_{2}$ emissions control, some low-carbon technologies are already being used. In particular, CCS technologies as an incorporated strategy are already playing a critical role in GHG management. Although scientists are making efforts to clean up the Earth, there is no common framework for CCS technological applications at present. As a result, the progress achieved in CCS technological development is at different levels and even overlapping. In this paper, we hope that the novel regulatory framework suggested can be useful in providing scholars with new inspiration for their research and in encouraging potential investors to focus on more mature technologies. By comparing the CCSTP S-curves with the conventional techno-paradigm, this paper also explained why CCSTP has a longer delay. In the final analysis and discussion, the major distinctions between the 
CCS techno-paradigm and the conventional commercialized techno-paradigm were identified as political barriers and public acceptance. Policy instruments and economic instruments are expected to play a pivotal role in the accomplishment of the global carbon reduction scenarios. Further, continuing political support and instruments, especially for CCS post-demonstration, are crucial to make CCS pilot plants commercially attractive to public and private investors. Apart from these factors, there are still many uncertainties about which technologies could lead to real improvements and which have no prospect in reducing anthropogenic $\mathrm{CO}_{2}$. Further work is required to evaluate the individual cases selected in this study.

\section{Acknowledgments}

This research is supported by the Major Bidding Program of the National Social Science Foundation of China (Grant No. 12\&ZD217). The authors would like to thank the anonymous referees for their insightful comments and suggestions to improve this paper, as well as the Uncertainty Decision-Making Laboratory and Low Carbon Technology and Economy Research Center of Sichuan University for helpful comments and discussion.

\section{Author Contributions}

The individual contribution and responsibilities of the authors were as follows: Jiuping Xu: Research idea and design, grant holder of research financing, modeling, participation in related article writing. Bobo Zheng: Research idea and design, literature mining, modeling, data collection, data analysis, diagrams mapping, article writing and formatting.

\section{Conflict of Interests}

The authors declare no conflicts of interest.

\section{References}

1. Chang, Y.; Yong, J. Differing perspectives of major oil firms on future energy developments: An illustrative framework. Energy Policy 2007, 35, 5466-5480.

2. Marchetti, C. On geoengineering and the $\mathrm{CO}_{2}$ problem. Clim. Chang. 1977, 1, 59-68.

3. Houghton, J.T.; Ding, Y.; Griggs, D.J. Climate Change 2001: The Scientific Basis; Cambridge University Press: Cambridge, UK, 2001; Volume 881.

4. Watson, R.T.; Albritton, D.L. Climate Change 2001: Synthesis Report: Third Assessment Report of the Intergovernmental Panel on Climate Change; Cambridge University Press: Cambridge, UK, 2001.

5. Peters, G.P.; Andrew, R.M.; Boden, T.; Canadell, J.G.; Ciais, P.; le Quere, C.; Marland, G.; Raupach, M.R.; Wilson, C. The challenge to keep global warming below $2{ }^{\circ}$ C. Nat. Clim. Chang. 2013, 3, 4-6.

6. Audus, H.; Freund, P.; Smith, A. Global Warming Damage and the Benefits of Mitigation; IEA Greenhouse Gas R\&D Programme: Paris, France, 1995. 
7. Li, J.; Colombier, M.; Giraud, P. Grappling with climate challenge in the built environment in China. J. Energy Eng. 2010, 136, 27-31.

8. Pacala, S.; Socolow, R. Stabilization wedges: Solving the climate problem for the next 50 years with current technologies. Science 2004, 305, 968-972.

9. Mathews, J.A. Carbon-negative biofuels. Energy Policy 2008, 36, 940-945.

10. International Energy Agency (IEA). IEA CCS Technology Roadmap; IEA: Paris, France, 2009.

11. Haszeldine, R.S. Carbon capture and storage: How green can black be? Science 2009, 325, 1647-1652.

12. IPCC. Intergovernmental Panel on Climate Change Special Report on Carbon Dioxide Capture and Storage; Cambridge University Press: Cambridge, UK, 2005.

13. Akimoto, K.; Tomoda, T. Costs and Technology Role for Different Levels of $\mathrm{CO}_{2}$ Concentration Stabilization; Avoiding Dangerous Climate Change, Cambridge University Press: Cambridge, UK, 2006; pp. 355-360.

14. Scott, V.; Gilfillan, S.; Markusson, N.; Chalmers, H.; Haszeldine, R.S. Last chance for carbon capture and storage. Nat. Clim. Chang. 2013, 3, 105-111.

15. IPCC. Climate Change 2014: Mitigation of Climate Change. Contribution of Working Group III to the Fifth Assessment Report of the Intergovernmental Panel on Climate Change; Cambridge University Press: Cambridge, UK; New York, NY, USA, 2014.

16. Department of Trade and Industry (DTI). Energy White Paper: Our Energy Future-Creating a Low Carbon Economy; DTI: London, UK, 2003.

17. Pearson, P.J.; Foxon, T.J. A low carbon industrial revolution? Insights and challenges from past technological and economic transformations. Energy Policy 2012, 50, 117-127.

18. Lüken, M.; Edenhofer, O.; Knopf, B.; Leimbach, M.; Luderer, G.; Bauer, N. The role of technological availability for the distributive impacts of climate change mitigation policy. Energy Policy 2011, 39, 6030-6039.

19. Kuhn, T. The Structure of Scientific Revolutions; University of Chicago Press: Chicago, IL, USA, 1962.

20. Dosi, G. Technological paradigms and technological trajectories: A suggested interpretation of the determinants and directions of technical change. Res. Policy 1982, 11, 147-162.

21. Freeman, C. The greening of technology and models of innovation. Technol. Forecast. Soc. Chang. 1996, 53, 27-39.

22. Van den Ende, J.; Dolfsma, W. Technology-push, demand-pull and the shaping of technological paradigms-patterns in the development of computing technology. J. Evol. Econ. 2005, 15, 83-99.

23. Grübler, A.; Nakićenović, N.; Victor, D.G. Dynamics of energy technologies and global change. Energy Policy 1999, 27, 247-280.

24. Bowen, F. Carbon capture and storage as a corporate technology strategy challenge. Energy Policy 2011, 39, 2256-2264.

25. Rai, V.; Victor, D.G.; Thurber, M.C. Carbon capture and storage at scale: Lessons from the growth of analogous energy technologies. Energy Policy 2010, 38, 4089-4098. 
26. Ridley, C.E.; Clark, C.M.; LeDuc, S.D.; Bierwagen, B.G.; Lin, B.B.; Mehl, A.; Tobias, D.A. Biofuels: Network analysis of the literature reveals key environmental and economic unknowns. Environ. Sci. Technol. 2012, 46, 1309-1315.

27. Scherf, M.; Epple, A.; Werner, T. The next generation of literature analysis: Integration of genomic analysis into text mining. Brief. Bioinform. 2005, 6, 287-297.

28. De Bruijn, B.; Martin, J. Getting to the (c) ore of knowledge: Mining biomedical literature. Int. J. Med. Inform. 2002, 67, 7-18.

29. Jensen, L.J.; Saric, J.; Bork, P. Literature mining for the biologist: From information retrieval to biological discovery. Nat. Rev. Genet. 2006, 7, 119-129.

30. Hirschman, L.; Park, J.C.; Tsujii, J.; Wong, L.; Wu, C.H. Accomplishments and challenges in literature data mining for biology. Bioinformatics 2002, 18, 1553-1561.

31. Marcotte, E.M.; Xenarios, I.; Eisenberg, D. Mining literature for protein-protein interactions. Bioinformatics 2001, 17, 359-363.

32. Garfield, E.; Merton, R.K. Citation Indexing: Its Theory and Application in Science, Technology, and Humanities; Wiley: New York, NY, USA, 1979; Volume 8.

33. Buchwald, H.; Avidor, Y.; Braunwald, E.; Jensen, M. D.; Pories, W.; Fahrbach, K.; Schoelles, K. Bariatric surgery: A systematic review and meta-analysis. JAMA 2004, 292, 1724-1737.

34. Protocol, K. (1997). "Kyoto Protocol.” UNFCCC Website. Available online: http://unfccc. int/kyoto_protocol/items/2830. php (accessed on 1 January 2011).

35. Ott, H.E.; Sterk, W.; Watanabe, R. The bali roadmap: New horizons for global climate policy. Clim. Policy 2008, 8, 91-95.

36. Buhre, B.; Elliott, L.; Sheng, C.; Gupta, R.; Wall, T. Oxy-fuel combustion technology for coal-fired power generation. Prog. Energy Combust. Sci. 2005, 31, 283-307.

37. Wall, T.F. Combustion processes for carbon capture. Proc. Combust. Inst. 2007, 31, 31-47.

38. Gibbins, J.; Chalmers, H. Carbon capture and storage. Energy Policy 2008, 36, 4317-4322.

39. Jordal, K.; Anheden, M.; Yan, J.; Strömberg, L. Oxyfuel combustion for coal-fired power generation with $\mathrm{CO}_{2}$ capture-opportunities and challenges. In Proceedings of the 7th International Conference on Greenhouse Gas Technologies, Vancouver, BC, Canada, 5-9 September 2004.

40. Olajire, A.A. $\mathrm{CO}_{2}$ capture and separation technologies for end-of-pipe applications-A review. Energy 2010, 35, 2610-2628.

41. Rydén, M.; Lyngfelt, A. Using steam reforming to produce hydrogen with carbon dioxide capture by chemical-looping combustion. Int. J. Hydrog. Energy 2006, 31, 1271-1283.

42. Barchas, R.; Davis, R. The Kerr-McGee/ABB lummus crest technology for the recovery of $\mathrm{CO}_{2}$ from stack gases. Energy Convers. Manag. 1992, 33, 333-340.

43. Feron, P.; Hendriks, C. $\mathrm{CO}_{2}$ capture process principles and costs. Oil Gas Sci. Technol. 2005, 60, 451-459.

44. Richter, H.J.; Knoche, K.F. Reversibility of Combustion Processes; ACS Symposium Series; ACS Publications: Washington, DC, USA, 1983; Volume 235, pp. 71-86.

45. Anheden, M.; Svedberg, G. Exergy analysis of chemical-looping combustion systems. Energy Convers. Manag. 1998, 39, 1967-1980. 
46. Ishida, M.; Jin, H.; Okamoto, T. A fundamental study of a new kind of medium material for chemical-looping combustion. Energy Fuels 1996, 10, 958-963.

47. Kanniche, M.; Gros-Bonnivard, R.; Jaud, P.; Valle-Marcos, J.; Amann, J.; Bouallou, C. Pre-combustion, post-combustion and oxy-combustion in thermal power plant for $\mathrm{CO}_{2}$ capture. Appl. Therm. Eng. 2010, 30, 53-62.

48. Hossain, M.M.; de Lasa, H.I. Chemical-looping combustion (CLC) for inherent $\mathrm{CO}_{2}$ separations-A review. Chem. Eng. Sci. 2008, 63, 4433-4451.

49. Mondal, M.K.; Balsora, H.K.; Varshney, P. Progress and trends in $\mathrm{CO}_{2}$ capture/separation technologies: A review. Energy 2012, 46, 431-441.

50. Nagamatsu, A.; Watanabe, C.; Shum, K. Diffusion trajectory of self-propagating innovations interacting with institutions-Incorporation of multi-factors learning function to model PV diffusion in Japan. Energy Policy 2006, 34, 411-421.

51. Griliches, Z. Hybrid corn: An exploration in the economics of technological change. Econometrica 1957, 25, 501-522.

52. Bachu, S. Sequestration of $\mathrm{CO}_{2}$ in geological media in response to climate change: Road map for site selection using the transform of the geological space into the $\mathrm{CO}_{2}$ phase space. Energy Convers. Manag. 200, 43, 87-102.

53. IPCC. Climate Change 2013: The Physical Science Basis. Contribution of Working Group I to the Fifth Assessment Report of the Intergovernmental Panel on Climate Change; Cambridge University Press: Cambridge, UK; New York, NY, USA, 2013.

54. Halmann, M.; Steinberg, M. Greenhouse Gas Carbon Dioxide Mitigation: Science and Technology; Lewis Publishers: Boca Raton, FL, USA, 1999.

55. Huntzinger, D.N.; Gierke, J.S.; Sutter, L.L.; Kawatra, S.K.; Eisele, T.C. Mineral carbonation for carbon sequestration in cement kiln dust from waste piles. J. Hazard. Mater. 2009, 168, 31-37.

56. Wee, J.-H. A review on carbon dioxide capture and storage technology using coal fly ash. Appl. Energy 2013, 106, 143-151.

57. Lackner, K.S.; Wendt, C.H.; Butt, D.P., Jr.; Joyce, E.L.; Sharp, D.H. Carbon dioxide disposal in carbonate minerals. Energy 1995, 20, 1153-1170.

58. Moazzem, S.; Rasul, M.; Khan, M. Energy recovery opportunities from mineral carbonation process in coal fired power plant. Appl. Therm. Eng. 2013, 51, 281-291.

59. Strazza, C.; del Borghi, A.; Gallo, M. Development of specific rules for the application of life cycle assessment to carbon capture and storage. Energies 2013, 6, 1250-1265.

60. Meng, K.; Williams, R.; Celia, M. Opportunities for low-cost $\mathrm{CO}_{2}$ storage demonstration projects in China. Energy Policy 2007, 35, 2368-2378.

61. Van Bergen, F.; Gale, J.; Damen, K.; Wildenborg, A. Worldwide selection of early opportunities for $\mathrm{CO}_{2}$-enhanced oil recovery and $\mathrm{CO}_{2}$-enhanced coal bed methane production. Energy 2004, 29, 1611-1621.

62. Koljonen, T.; Siikavirta, H.; Zevenhoven, R.; Savolainen, I. $\mathrm{CO}_{2}$ capture, storage and reusepotential in finland. Energy 2004, 29, 1521-1527. 
63. Hovorka, S.; Tinker, S. EOR as sequestration-geoscience perspective. In Proceedings of the MIT Symposium on Role of EOR in Accelerative Deployment of CCS, Cambridge, MA, USA, 23 July 2010.

64. Dahowski, R.; Dooley, J. Carbon management strategies for us electricity generation capacity: A vintage-based approach. Energy 2004, 29, 1589-1598.

65. De Silva, P.; Ranjith, P.; Choi, S. A study of methodologies for $\mathrm{CO}_{2}$ storage capacity estimation of coal. Fuel 2012, 91, 1-15.

66. Alvarado, V.; Manrique, E. Enhanced oil recovery: An update review. Energies 2010, 3, 1529-1575.

67. Li, L.; Zhao, N.; Wei, W.; Sun, Y. A review of research progress on $\mathrm{CO}_{2}$ capture, storage, and utilization in chinese academy of sciences. Fuel 2013, 108, 112-130.

68. Wei, X.; Massarotto, P.; Wang, G.; Rudolph, V.; Golding, S.D. $\mathrm{CO}_{2}$ sequestration in coals and enhanced coalbed methane recovery: New numerical approach. Fuel 2010, 8, 1110-1118.

69. Edenhofer, O.; Knopf, B.; Barker, T.; Baumstark, L.; Bellevrat, E.; Chateau, B.; Criqui, P.; Isaac, M.; Kitous, A.; Kypreos, S.; et al. The economics of low stabilization: Model comparison of mitigation strategies and costs. Energy J. 2010, 31, 11-48.

70. Erlach, B.; Harder, B.; Tsatsaronis, G. Combined hydrothermal carbonization and gasification of biomass with carbon capture. Energy 2012, 45, 329-338.

71. Metz, B.; Davidson, O.R. Climate Change 2007: Mitigation: Contribution of Working Group III to the Fourth Assessment Report of the Intergovernmental Panel on Climate Change; Intergovernmental Panel on Climate Change: Geneva, Switzerland, 2007.

72. Azar, C.; Lindgren, K.; Larson, E.; Möllersten, K. Carbon capture and storage from fossil fuels and biomass-costs and potential role in stabilizing the atmosphere. Clim. Chang. 2006, 74, 47-79.

73. Ricci, O.; Selosse, S. Global and regional potential for bioelectricity with carbon capture and storage. Energy Policy 2013, 52, 689-698.

74. Schmidt, J.; Leduc, S.; Dotzauer, E.; Schmid, E. Cost-effective policy instruments for greenhouse gas emission reduction and fossil fuel substitution through bioenergy production in Austria. Energy Policy 2011, 39, 3261-3280.

75. Möllersten, K.; Yan, J.; Moreira, J.R. Potential market niches for biomass energy with $\mathrm{CO}_{2}$ capture and storage-Opportunities for energy supply with negative $\mathrm{CO}_{2}$ emissions. Biomass Bioenergy 2003, 25, 273-285.

76. Rhodes, J.S.; Keith, D.W. Engineering economic analysis of biomass IGCC with carbon capture and storage. Biomass Bioenergy 2005, 29, 440-450.

77. Friedlingstein, P.; Solomon, S.; Plattner, G.; Knutti, R.; Ciais, P.; Raupach, M. Long-term climate implications of twenty-first century options for carbon dioxide emission mitigation. Nat. Clim. Chang. 2011, 1, 457-461.

78. Gough, C.; Upham, P. Biomass Energy with Carbon Capture and Storage (BECCS): A Review; Working Paper, 147; Tyndall Centre for Climate Change Research: Manchester, UK, 2010.

79. Ricci, O. Providing adequate economic incentives for bioenergies with $\mathrm{CO}_{2}$ capture and geological storage. Energy Policy 2012, 44, 362-373. 
80. Obersteiner, M.; Azar, C.; Kauppi, P.; Möllersten, K.; Moreira, J.; Nilsson, S.; Read, P.; Riahi, K.; Schlamadinger, B.; Yamagata, Y.; et al. Managing climate risk. Science 2001, 294, 786-787.

81. Grönkvist, S.; Möllersten, K.; Pingoud, K. Equal opportunity for avoided $\mathrm{CO}_{2}$ emissions: A step towards more cost-effective climate change mitigation regimes. Mitig. Adapt. Strateg. Glob. Chang. 2006, 11, 1083-1096.

82. Song, C. Global challenges and strategies for control, conversion and utilization of $\mathrm{CO}_{2}$ for sustainable development involving energy, catalysis, adsorption and chemical processing. Catal. Today 2006, 115, 2-32.

83. Read, P.; Lermit, J. Bio-energy with carbon storage (BECS): A sequential decision approach to the threat of abrupt climate change. Energy 2005, 30, 2654-2671.

84. International Energy Agency (IEA). A Policy Strategy for Carbon Capture and Storage; IEA: Paris, France, 2012.

85. Dales, J.H.; Pollution, P. Prices: An Essay in Policy-Making and Economics; University of Toronto Press: Toronto, ON, USA, 1968.

86. Oh, T.H. Carbon capture and storage potential in coal-fired plant in Malaysia-A review. Renew. Sustain. Energy Rev. 2010, 14, 2697-2709.

87. Scott, V. What can we expect from europe's carbon capture and storage demonstrations? Energy Policy 2013, 54, 66-71.

(c) 2014 by the authors; licensee MDPI, Basel, Switzerland. This article is an open access article distributed under the terms and conditions of the Creative Commons Attribution license (http://creativecommons.org/licenses/by/3.0/). 